\title{
Fuel-Cladding Interaction Layers in Irradiated U-Zr and U-Pu-Zr Fuel Elements
}

prepared by

Engineering Technology Division

Argonne National Laboratory-West 


\section{About Argonne National Laboratory}

Argonne is managed by The University of Chicago for the U.S. Department of Energy under contract W-31-109-Eng-38. The Laboratory's main facility is outside Chicago, at 9700 South Cass Avenue, Argonne, Illinois 60439. For information about Argonne and its pioneering science and technology programs, see www.anl.gov.

\section{Availability of This Report}

This report is available, at no cost, at http://www.osti.gov/bridge. It is also available on paper to U.S. Department of Energy and its contractors, for a processing fee, from:

U.S. Department of Energy

Office of Scientific and Technical Information

P.O. Box 62

Oak Ridge, TN 37831-0062

phone (865) 576-8401

fax (865) 576-5728

reports@adonis.osti.gov

\section{Disclaimer}

This report was prepared as an account of work sponsored by an agency of the United States Government. Neither the United States Government nor any agency thereof, nor The University of Chicago, nor any of their employees or officers, makes any warranty, express or implied, or assumes any legal liability or responsibility for the accuracy, completeness, or usefulness of any information, apparatus, product, or process disclosed, or represents that its use would not infringe privately owned rights. Reference herein to any specific commercial product, process, or service by trade name, trademark, manufacturer, or otherwise, does not necessarily constitute or imply its endorsement, recommendation, or favoring by the United States Government or any agency thereof. The views and opinions of document authors expressed herein do not necessarily state or reflect those of the United States Government or any agency thereof, Argonne National Laboratory, or The University of Chicago. 


\section{Fuel-Cladding Interaction Layers in Irradiated U-Zr and U-Pu-Zr Fuel Elements}

by

D.D. Keiser*

Engineering Technology Division, Argonne National Laboratory-West

*Current Affiliation: Idaho National Laboratory, P.0.Box 1625, Idaho Falls, ID 83415
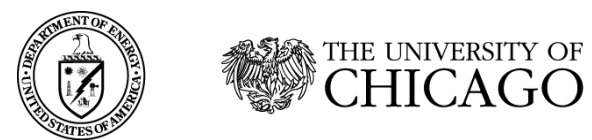

Argonne National Laboratory is managed by

The University of Chicago for the U.S. Department of Energy 


\section{TABLE OF CONTENTS}

Page

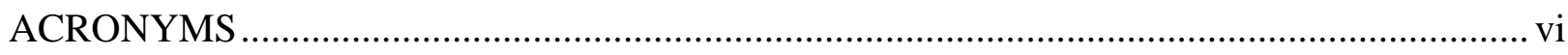

ABSTRACT ........................................................................................................

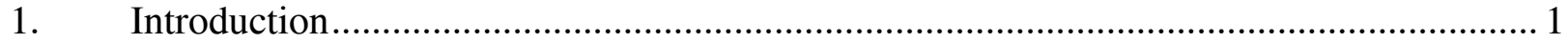

2. Result of Post Irradiation Analyses of Fuel Elements ................................................. 2

2.1 Layers in Fuel Elements with HT9 Cladding ……............................................ 4

2.1.1 HT9-Clad Elements with Ternary U-Pu-Zr Alloy Fuel............................... 4

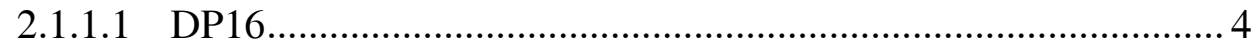

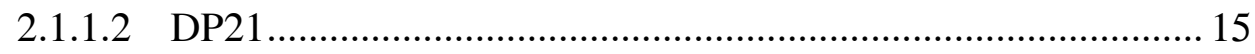

2.1.2 HT9-Clad Elements with Binary U-Zr Alloy Fuel ................................... 15

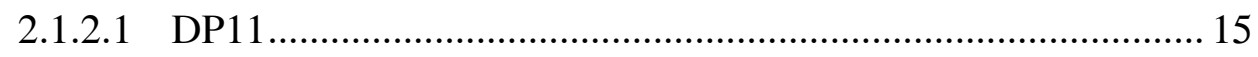

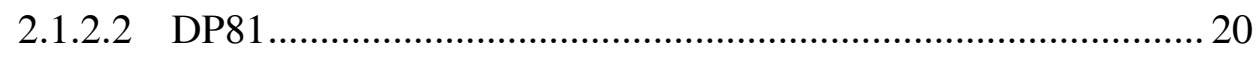

2.1.2.3 Breached Fuel Elements............................................................ 20

2.2 Layers in Fuel Elements with D9 or Type 316 Stainless Steel Cladding ............ 20

2.2.1 D9-Clad Elements with Ternary U-Pu-Zr Alloy Fuel .............................. 20

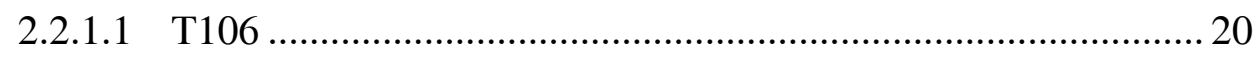

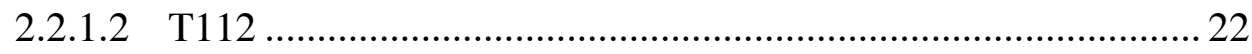

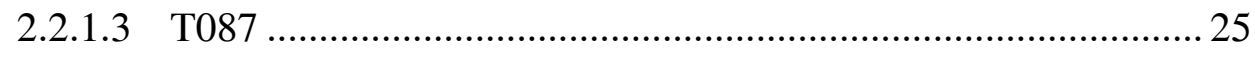

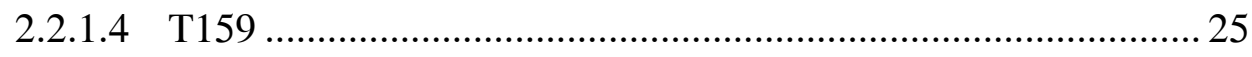

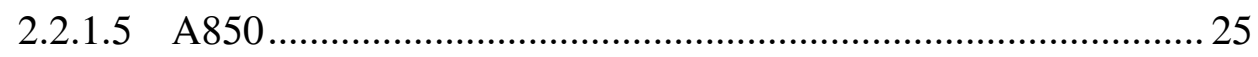

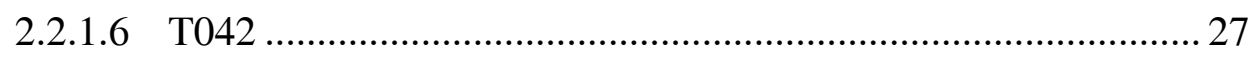

2.2.2 D9-Clad Elements with Binary U-Zr Alloy Fuel..................................... 27

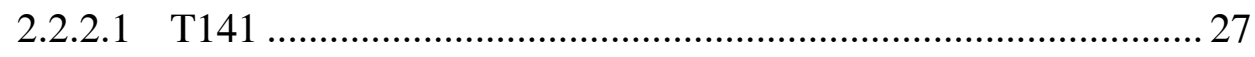

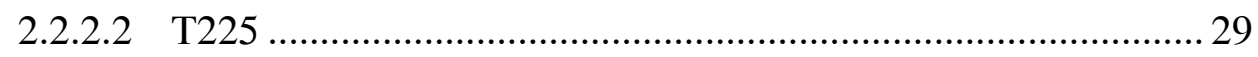

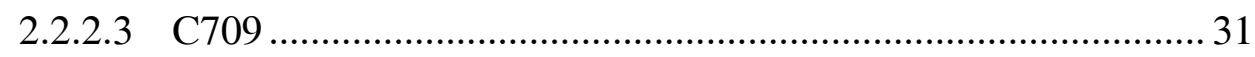

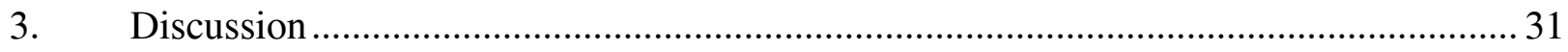

3.1 Phases Found at the Fuel-Cladding Interface in Irradiated $\mathrm{U}-\mathrm{Zr}$ and U-Pu-Zr Fuel Elements Clad with D9, Type 316, or HT9 Stainless Steel ........... 31

3.2 Factors Affecting Interaction Zone Thickness in Irradiated Fuel Elements ......... 33

3.3 Potential Components to be Carried Over into a Metal Waste Form ................... 33

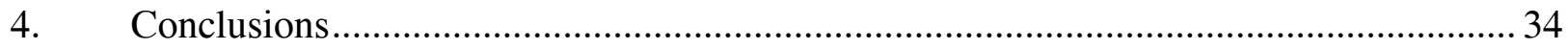

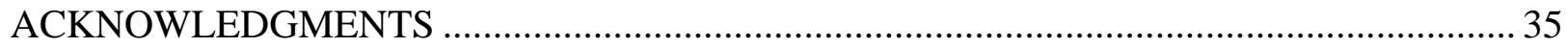

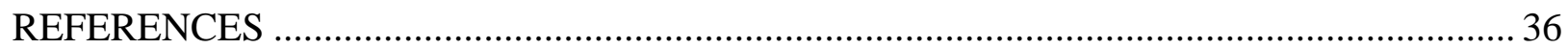




\section{LIST OF FIGURES}

Page

1. Optical Micrograph of Typical Fuel-cladding Interface from DP-16 Samples ....................5

2. Optical Micrograph Showing the Accumulation of Fission Product

Phases at the Fuel-cladding Interface

3. Electron Microprobe Specimen Current Image and X-ray Maps for

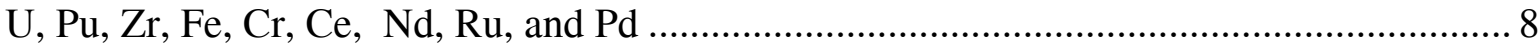

4. Relative EPMA Concentration Profiles for $\mathrm{U}, \mathrm{Zr}, \mathrm{Pu}, \mathrm{Fe}, \mathrm{Cr}, \mathrm{Ce}$, and Nd Across the Fuel-Cladding Interface for DP16.

5. Secondary Electron Micrographs of a Cladding Sample Taken from DP-16, Low Magnification Image of the Sample, and the Outlined Box Identifies the Region Where Subsequent Analyses were Focused, Specifically at Locations A and B,

(b) Shows a Higher Magnification Image of Region A and (c) Shows Region B

6. Backscattered Electron (a) and Secondary Electron (b) Images of the Interaction Layers Observed in Location A for the Sample Taken from DP16

7. Measured Compositions as a Function of Linear Position in Location A... 12

8. Backscattered Electron and Secondary Electron Images of the Interaction Layers

Observed in Location B for the Sample Taken from DP16.

9. Measured Compositions as a Function of Linear Position in Location A

Shows Elemental Traces for Cladding Constituents and Shows Traces for

the Fission Products

10. Electron Microprobe Specimen Current Image and X-ray Maps for U, Zr, Fe,

$\mathrm{Cr}, \mathrm{Ba}, \mathrm{La}, \mathrm{Ce}, \mathrm{Pr}, \mathrm{Nd}$, and $\mathrm{Sm}$.

11. Optical Micrograph of an Area Near the Fuel-Cladding Interface Where

Dark-Gray Precipitates and Light-Gray Precipitates are Observed

12. Optical Micrograph Showing the Presence of Blocky Particles Near the Fuel-Cladding Interface.

13. Optical Micrograph Showing the Presence of an Interaction Zone at the Fuel-Cladding Interface

14. Optical Micrograph Showing The Presence of a Fuel-cladding Interaction Zone and Large Quantities of Fission Products Filling Voids Near the Cladding

15. Optical Micrograph Showing the Fuel-cladding Interface Near An Intact

Zr-rind Layer

16. Optical Micrograph Showing Fuel-Cladding Interaction Adjacent to a Large

Deposit of Lanthanide Fission Products

17. Optical Micrographs Showing A Low Magnification Image and High Magnification Image of the Fuel-cladding Interface Where The Zr-rind

Is Not Intact and Interaction Has Occurred Between the Fuel and Cladding.................... 28

18. Optical Micrograph Showing the Fuel-cladding Interaction That Has

Occurred in an Area Where the Zr-rind Is Not Intact.

19. Optical Micrographs of a Transverse Cross-section Taken From The Bottom of Element T-225 


\section{LIST OF TABLES}

Page

1. Nominal Compositions for Stainless Steel Cladding Materials ....................................... 1

2. Results From Examinations of Fuel Elements Irradiated in EBR-II ................................ 3

3. Approximate Compositions of Spot Readings Taken in Different Regions of the Phase Layers at Location A of DP16 SEM Sample ............................................... 11

4. Approximate Compositions of Spot Readings of Phase Layers at Location B of DP16 SEM Sample............................................................................ 13

5. Approximate Compositions of Light and Dark Regions of Noble Metal-Containing Phases in a Sample From Fuel Element T106.................................. 21

6. As-Irradiated Data For Samples From Fuel Element A850 ....................................... 25 


\section{ACRONYMS}

$\begin{array}{ll}\text { ANL } & \text { Argonne National Laboratory } \\ \text { BOL } & \text { Beginning-Of-Life } \\ \text { EBR-II } & \text { Experimental Breeder Reactor-II } \\ \text { EDS } & \text { Energy Dispersive Spectroscopy } \\ \text { EPMA } & \text { Electron Probe Micro-Analysis } \\ \text { ID } & \text { Inner Diameter } \\ \text { OM } & \text { Optical Metallography } \\ \text { PICT } & \text { Peak Inner Cladding Temperature } \\ \text { SEM } & \text { Scanning Electron Microscope } \\ \text { SS } & \text { Stainless Steel } \\ \text { WDS } & \text { Wavelength Dispersive Spectroscopy }\end{array}$




\title{
FUEL-CLADDING INTERACTION LAYERS IN IRRADIATED U-ZR AND U-PU-ZR FUEL ELEMENTS
}

by

D. D. Keiser

\begin{abstract}
Argonne National Laboratory is developing an electrometallurgical treatment for spent nuclear fuels. The initial demonstration of this process is being conducted on U-Zr and U-Pu-Zr alloy fuel elements irradiated in the Experimental Breeder Reactor-II (EBR-II). The electrometallurgical treatment process extracts usable uranium from irradiated fuel elements and places residual fission products, actinides, process $\mathrm{Zr}$, and cladding hulls (small segments of tubing) into two waste forms - a ceramic and a metal alloy. The metal waste form will contain the cladding hulls, $\mathrm{Zr}$, and noble metal fission products, and it will be disposed of in a geologic repository. As a result, the expected composition of the waste form will need to be well understood. This report deals with the condition of the cladding, which will make up a large fraction of the metal waste form, after irradiation in EBR-II and before insertion into the electrorefiner. Specifically, it looks at layers that can be found on the inner surface of the cladding due to in-reactor interactions between the alloy fuel and the stainless steel cladding that occurs after the fuel has swelled and contacted the cladding. Many detailed examinations of fuel elements irradiated in EBR-II have been completed and are discussed in the context of interaction layer formation in irradiated cladding. The composition and thickness of the developed interaction layers are identified, along with the irradition conditions, cladding type, and axial location on fuel elements where the thickest interaction layers can be expected to develop. It has been found that the largest interaction zones are observed at combined high power and high temperature regions of fuel elements and for fuel elements wiht U-Pu-Zr alloy fuel and D9 stainless steel cladding. The most prevalent, non-cladding constituent observed in the developed interaction layers are the lanthanide fission products
\end{abstract}




\section{Introduction}

Argonne National Laboratory is developing an electrometallurgical treatment for spent nuclear fuels [1]. This process utilizes chopped fuel segments that are placed in anode dissolution baskets that are immersed in a eutectic $\mathrm{LiCl}-\mathrm{KCl}$ salt in a constructed electro-refiner. Current is applied to dissolve uranium, actinides, and fission products from the cladding segments (hulls), and the uranium is deposited on a stainless steel (SS) mandrel that serves as a cathode. The small cladding hulls, noble metal fission products (noble metals describes those metals that are noble to the electrometallurgical treatment process and include metals like $\mathrm{Tc}, \mathrm{Pd}, \mathrm{Ru}, \mathrm{Rh}, \mathrm{Zr}, \mathrm{Ag}$, etc.), and most of the zirconium, a constituent of the metallic fuel, are left behind in the anode baskets. The actinides and active fission products are left in the $\mathrm{LiCl}-\mathrm{KCl}$ eutectic salt electrolyte. These components are later extracted from the salt through ion-exchange into zeolite which is in turn mixed with glass to form a ceramic waste form [2]. The cladding hulls, process $\mathrm{Zr}$, and noble metal fission products are melted and solidified as a metal waste form ingot [3]. Both the ceramic and metal waste form will be disposed of in a geologic repository.

As part of the demonstration of the process, fuel elements that have been irradiated in the Experimental Breeder Reactor II (EBR-II) are being treated. These fuel elements have either $\mathrm{U}-10 \mathrm{wt} \% \mathrm{Zr}$ or U-x wt\% (xz6) Pu-10 wt\% Zr as the fuel and the martensitic stainless steel HT9 or the austenitic stainless steel D9 or Type 316 as the cladding. The nominal compositions of the cladding materials are listed in Table 1. The fuel elements that have been irradiated in EBR-II were exposed to a variety of conditions (different temperatures, burn-ups, power, etc.). Changes in these parameters occurred at different locations in the core and along the length of the individual fuel elements. As fuel elements were irradiated for longer times, the inventory of fission products continued to grow and over time the fission products were found to migrate towards the fuel/cladding interface [4]. Eventually, the fuel contacted the cladding and localized interaction occurred, which resulted in diffusion of lanthanide fission products (and minor amounts of other fission products) along with $\mathrm{U}$ and Pu from the fuel into the cladding [5]. In addition, the Fe and Ni interdiffused from the cladding into the fuel. Phases that not only contain lanthanide fission products but that also contain noble metal fission products have been observed in the vicinity of the fuel-cladding interface [4].

Table 1. Nominal Compositions for Stainless Steel Cladding Materials (wt\%) ${ }^{1}$

\begin{tabular}{|l|c|c|l|}
\hline & HT9 & D9 & \multicolumn{1}{|c|}{316} \\
\hline \hline $\mathrm{Ni}$ & 0.5 & 15.5 & $10-14$ \\
\hline $\mathrm{Cr}$ & 12.0 & 13.5 & $16-18$ \\
\hline $\mathrm{Mn}$ & 0.2 & 2.0 & 2 (max) \\
\hline $\mathrm{Mo}$ & 1.0 & 2.0 & $2-3$ \\
\hline $\mathrm{Si}$ & 0.25 & 0.75 & 1 (max) \\
\hline $\mathrm{Ti}$ & - & 0.25 & - \\
\hline $\mathrm{C}$ & 0.2 & 0.04 & 0.08 (max) \\
\hline
\end{tabular}


Table 1. (Contd.)

\begin{tabular}{|l|c|c|c|}
\hline & HT9 & D9 & \multicolumn{1}{|c|}{316} \\
\hline \hline $\mathrm{W}$ & 0.5 & - & - \\
\hline $\mathrm{V}$ & 0.5 & - & - \\
\hline $\mathrm{S}$ & - & - & $0.03(\max )$ \\
\hline $\mathrm{P}$ & - & - & $0.045(\max )$ \\
\hline
\end{tabular}

1. Balance iron.

These phases at the fuel-cladding interface are of interest since they may contain components that will end up in the metal waste form, unless the phases are dissolved away in the electrorefiner. This possibility of having a variety of elements on the inner surfaces of the cladding hulls that will be consolidated into a waste form ingot for repository disposal provides the impetus for this investigation. This paper was written to describe, in reasonable detail, the development of interaction layers on the inner surface of cladding, based on post-irradiation examinations of EBR-II fuel elements. In particular, the composition and thickness of the interaction layers are discussed, along with the irradiation conditions, cladding type, and axial location on a fuel element where the thickest interaction layers can be expected to develop. Because noble metal components will also be incorporated into the metal waste form, comments are made on the appearance of noble metal-containing phases that appear near the inner cladding surface in irradiated fuels. This paper is organized to focus on interaction layer development in the irradiated fuel elements according to the cladding type, and it includes fuel elements clad with Types HT9, D9, and 316 stainless steel.

\section{Result of Post Irradiation Analyses of Fuel Elements}

Table 2 summarizes the results that will be discussed in this paper. The table gives the fuel compositions (all fuel compositions will be listed in at\% so correlations can be made with observed phases), the cladding material, the local burn-up, the fuel surface temperature at the analysis location, the thickness of the total diffusion layer, the analysis instrument, and the prominent fuel and fission product constituents found in the cladding. Sample analyses have been completed using optical metallography (OM), scanning electron microscopy (SEM), and/or electron probe micro-analysis (EPMA). 
Table 2. Results From Examinations of Fuel Elements Irradiated in EBR-II

\begin{tabular}{|c|c|c|c|c|c|c|c|}
\hline $\begin{array}{l}\text { Fuel } \\
\text { Element } \\
\text { ID }\end{array}$ & $\begin{array}{l}\text { Cladding } \\
\text { Material }\end{array}$ & $\begin{array}{c}\text { Fuel } \\
\text { Composition } \\
\text { (at\%) }\end{array}$ & $\begin{array}{l}\text { Burnup } \\
\text { (at\%) }\end{array}$ & $\begin{array}{l}\text { Temp at } \\
\text { Fuel/ } \\
\text { Clad Inter- } \\
\text { face at BOL } \\
\text { (C) })^{1}\end{array}$ & $\begin{array}{l}\text { Maximum } \\
\text { Zone } \\
\text { Thickness } \\
\text { Observed } \\
(\mu \mathrm{m})\end{array}$ & $\begin{array}{c}\text { Type of } \\
\text { Analysis }\end{array}$ & $\begin{array}{l}\text { Components } \\
\text { Originating in the } \\
\text { Fuel That Are } \\
\text { Found in } \\
\text { Cladding Layers }\end{array}$ \\
\hline DP81 & HT9 & U-23Zr & 5.0 & 660 & 70 & EPMA & Ce, Pr, Nd \\
\hline DP11 & HT9 & U-23Zr & 10.0 & 660 & 90 & EPMA & $\begin{array}{l}\text { Ce, Pr, Nd, } \\
\text { La,Sm,Pd }\end{array}$ \\
\hline DP04 & HT9 & U-23Zr & 10.0 & 660 & 90 & EPMA & $\begin{array}{l}\text { Ce, Pr, Nd, } \\
\text { La,Sm,Pd }\end{array}$ \\
\hline DP70 ${ }^{2}$ & HT9 & U-23Zr & 10.0 & 660 & 140 & EPMA & $\begin{array}{l}\text { Ce, Pr, Nd, } \\
\text { La,Sm,Pd }\end{array}$ \\
\hline DP75 & HT9 & U-23Zr & 10.0 & 660 & 170 & EPMA & $\begin{array}{l}\text { Ce, Pr, Nd, } \\
\text { La,Sm,Pd }\end{array}$ \\
\hline T459 & HT9 & U-16Pu-23Zr & 3.0 & $\mathrm{ND}^{3}$ & 10 & EPMA & Ce, Pr, Nd \\
\hline DP16(1) & HT9 & $\mathrm{U}-16 \mathrm{Pu}-23 \mathrm{Zr}$ & 9.7 & 540 & 40 & SEM & $\begin{array}{l}\text { Ce,Nd,La, } \\
\text { U,Pu,Pd }\end{array}$ \\
\hline DP16(2) & HT9 & U-16Pu-23Zr & 10.1 & 550 & 40 & EPMA & $\mathrm{Ce}, \mathrm{Nd}, \mathrm{Pr}, \mathrm{Pu}$ \\
\hline DP21 & HT9 & $\mathrm{U}-16 \mathrm{Pu}-23 \mathrm{Zr}$ & 11.4 & ND & ND & EPMA & ND \\
\hline C709 & D9 & U-23Zr & 9.3 & 650 & 111 & EPMA & $\mathrm{Ce}, \mathrm{Nd}, \mathrm{La}$ \\
\hline $\mathrm{T} 225$ & D9 & U-23Zr & 10.0 & ND & 25 & $\mathrm{OM}$ & ND \\
\hline T141 & D9 & U-23Zr & 11.9 & ND & 17 & $\mathrm{OM}$ & ND \\
\hline T159 & D9 & $\mathrm{U}-16 \mathrm{Pu}-23 \mathrm{Zr}$ & 3.0 & ND & ND & EPMA & $\mathrm{Ce}, \mathrm{Pr}, \mathrm{Nd}, \mathrm{Pu}$ \\
\hline 4 & D9 & U-16Pu-23Zr & 6.0 & ND & 75 & EPMA & Ce,Pr,Nd,La \\
\hline T042 & D9 & U-7Pu-23Zr & 6.0 & 540 & 20 & EPMA & $\mathrm{Ce}, \mathrm{Pr}, \mathrm{Nd}, \mathrm{La}$ \\
\hline T087 & D9 & U-16Pu-23Zr & 10.0 & ND & 50 & EPMA & Ce,Pr,Nd,La, Pu \\
\hline A850 & D9 & U-16Pu-23Zr & 10.1 & 550 & 100 & EPMA & $\mathrm{Ce}, \mathrm{Nd}, \mathrm{La}, \mathrm{Pu}$ \\
\hline T112 & D9 & U-16Pu-23Zr & 11.9 & ND & 72 & EPMA & ND \\
\hline T106 & D9 & U-16Pu-23Zr & 17.0 & ND & 20 & EPMA & $\mathrm{Ce}, \mathrm{Pr}, \mathrm{Nd}, \mathrm{La}$ \\
\hline T341 & 316SS & U-16Pu-23Zr & 0.4 & ND & ND & EPMA & ND \\
\hline
\end{tabular}

1. Temperatures calculated for beginning of life (BOL) of fuel elements using the computer code LIFEMETAL.

2. DP70 and DP75 were fuel elements run in the reactor beyond breach of the cladding.

3. Not determined.

4. The label for this fuel element was not found. 


\subsection{Layers in Fuel Elements with HT9 Cladding}

Referring to Table 2, nine irradiated fuel elements clad with the martensitic stainless steel HT9 have been analyzed with particular focus on the fuel-cladding interface. Three elements had U-16 at\% Pu-23 at\% Zr fuel, while the rest had U-23 at\% Zr fuel.

\subsubsection{HT9-Clad Elements with Ternary U-Pu-Zr Alloy Fuel}

\subsubsection{DP16}

Fuel element DP16 consisted of U-16Pu-23Zr fuel and HT9 cladding and was irradiated to a burn-up of 11.3 at\%. This element is of particular interest since it was the only fuel element where a sample was sliced from the element and analyzed using scanning electron microscope/ energy dispersive spectroscopy (SEM/EDS), in addition to the more typical optical metallography and EPMA analyses historically performed on fuel elements.

The optical metallography and EPMA analysis for DP16 was performed on a sample from a position of $\mathrm{x} / \mathrm{L}=0.78(\mathrm{x} / \mathrm{L}$ refers to the radial position from the bottom of the fuel element, $\mathrm{x}$, divided by the total length of the fuel element, L) (with a local burn-up of 10.1 at\%). The observations at the fuel-cladding interface for this fuel element proved to be representative of what was observed for the other U-16Pu-23Zr/HT9 fuel elements, based on EPMA and optical metallography.

Figure 1 shows an optical micrograph of a small region of the fuel-cladding interface in fuel element DP16. Interdiffusion layers are observed on the inner-surface of the cladding. Another optical metallograph is presented in Fig. 2 that shows some of the fission product phases that can be found in regions of the fuel near the cladding. 


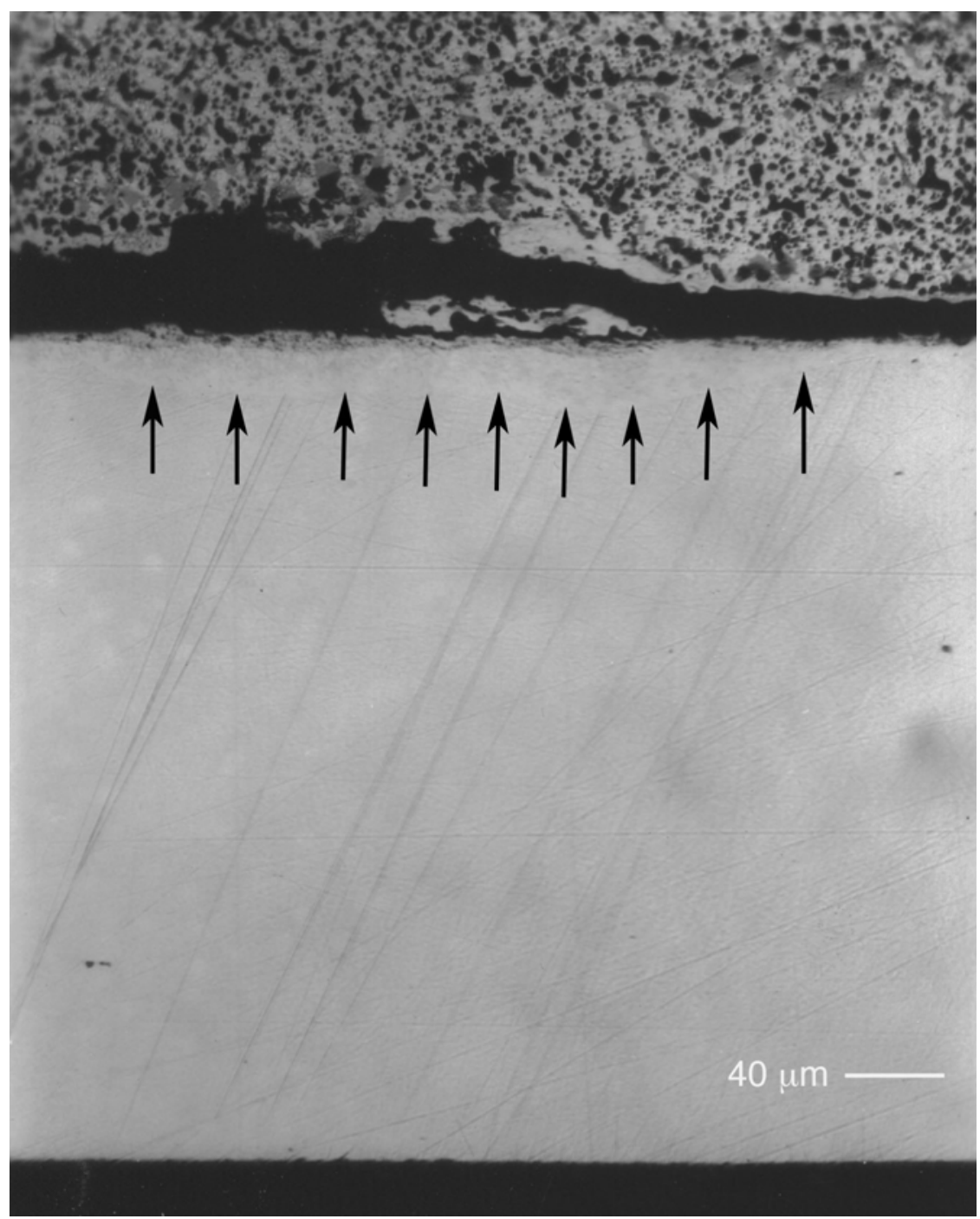

Fig. 1. Optical Micrograph of Typical Fuel-cladding Interface from DP-16 Samples (note interaction on the cladding side of the interface [black arrows]) 


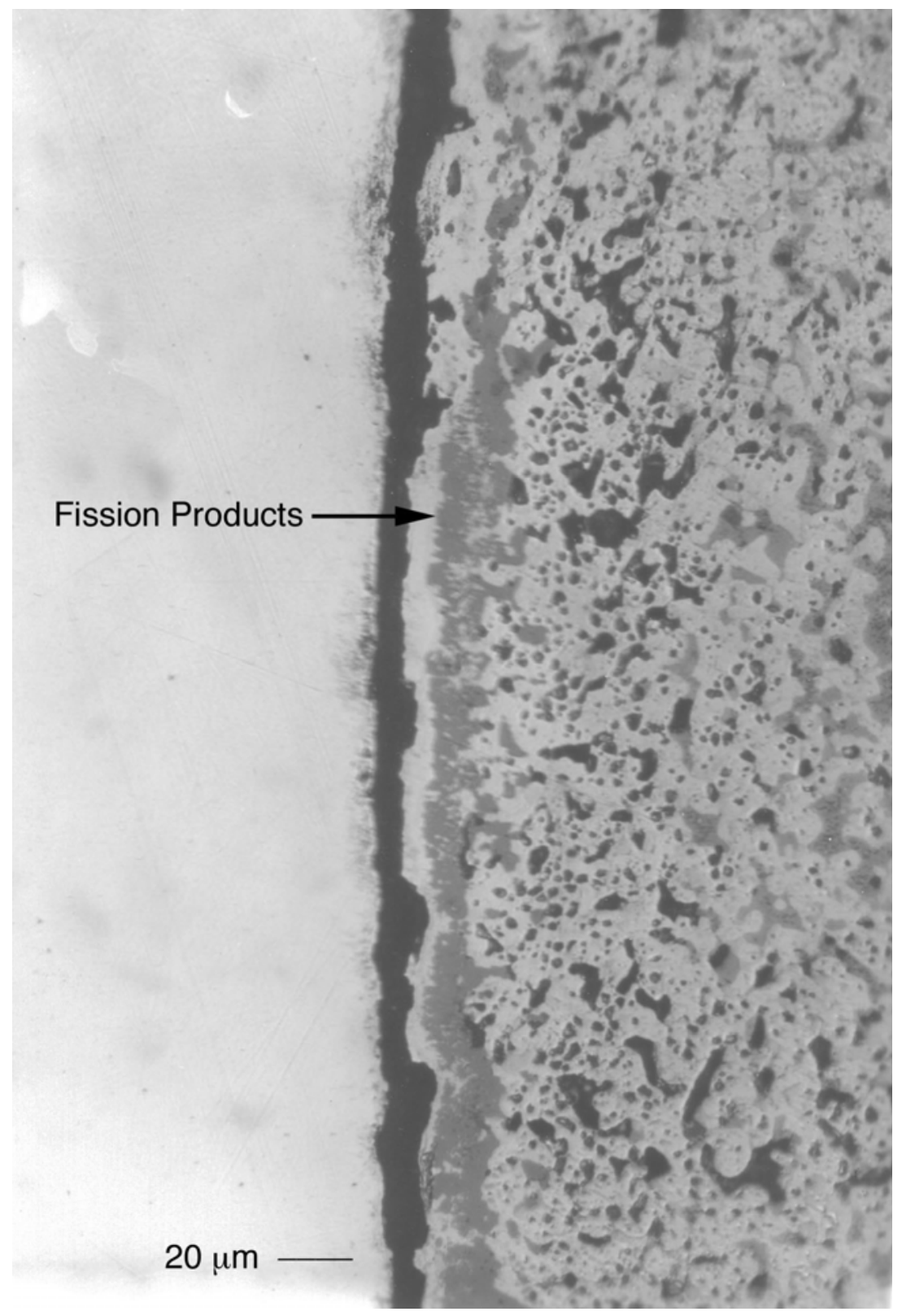

Fig. 2. Optical Micrograph Showing the Accumulation of Fission Product Phases at the Fuel-cladding Interface

Figure 3 shows a specimen current image and X-ray maps, produced using EPMA, of a region in the vicinity of the fuel-cladding interface. X-ray maps were generated for the fuel constituents $\mathrm{U}, \mathrm{Pu}$, and $\mathrm{Zr}$; the cladding components $\mathrm{Fe}$ and $\mathrm{Cr}$; and the fission products $\mathrm{Ce}, \mathrm{Nd}, \mathrm{Pd}$, and $\mathrm{Ru}$. The X-ray maps for $\mathrm{Cr}$ and $\mathrm{Ru}$ are not shown since $\mathrm{Cr}$ did not appear to diffuse into the fuel (but the Cr concentration was elevated in the immediate vicinity of the fuel-cladding interface), and $\mathrm{Ru}$ traced the $\mathrm{Pu}$ and is observed in the same localized regions of the fuel, but in slightly lower amounts. Based on the shown X-ray maps, Fe diffuses into the fuel, Ce and Nd diffuse into the cladding, and Pd enriches in localized areas of the fuel near the fuel-cladding interface. 


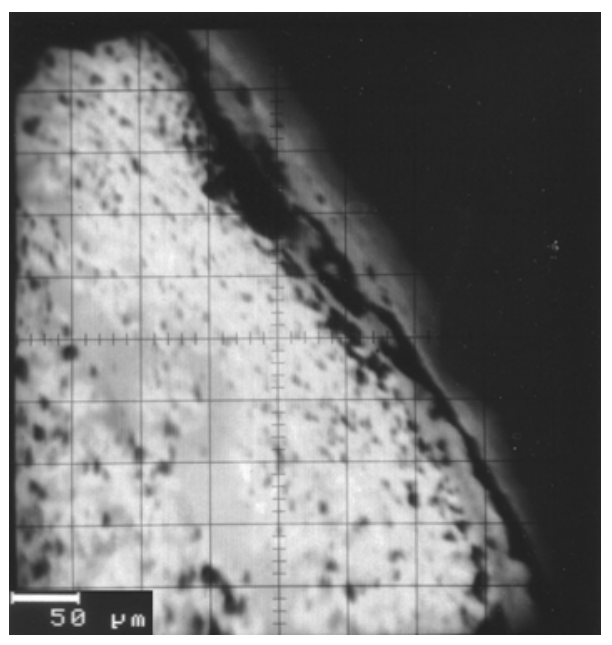

(a)

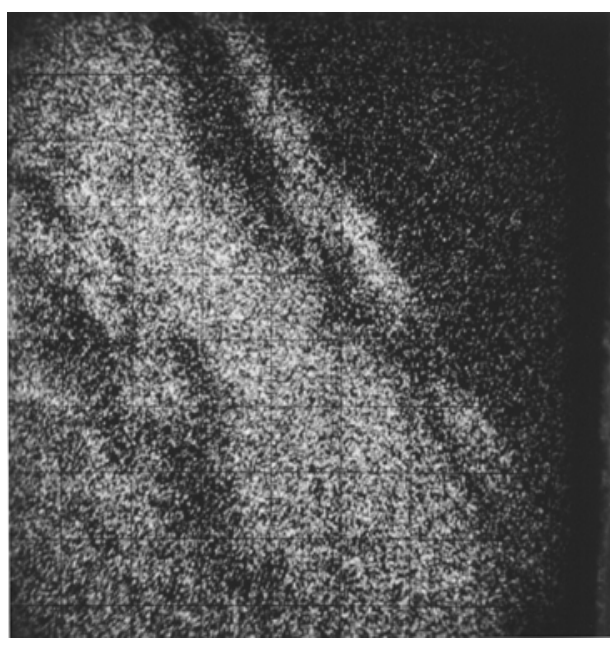

(c)

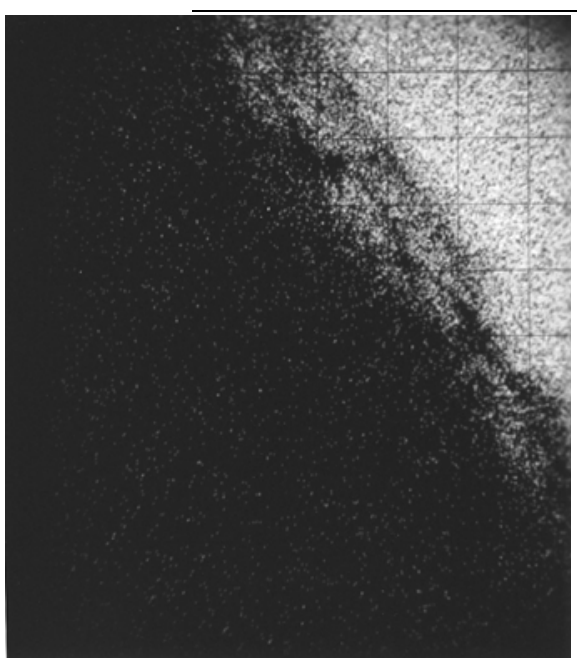

(e)

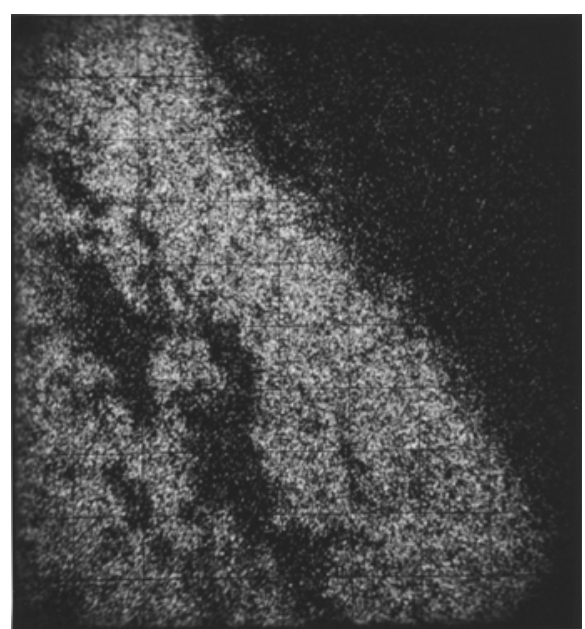

(b)

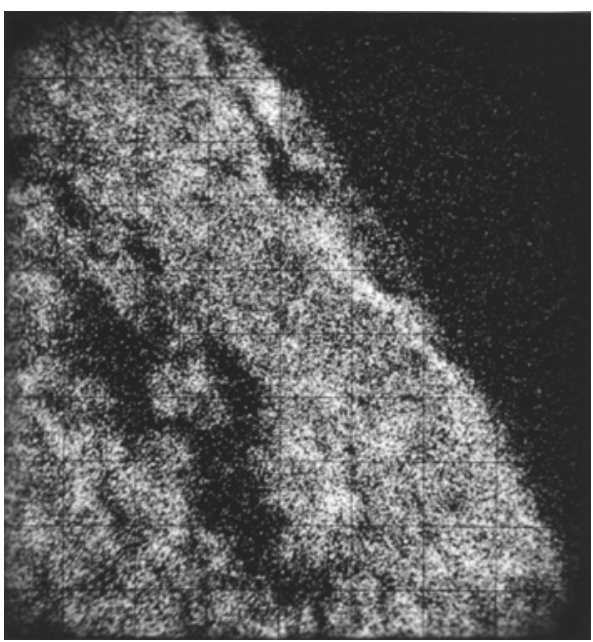

(d)

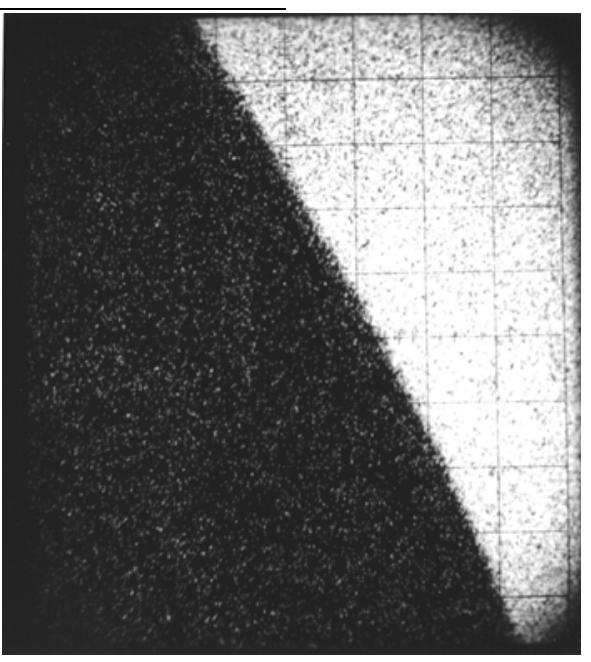

(f) 


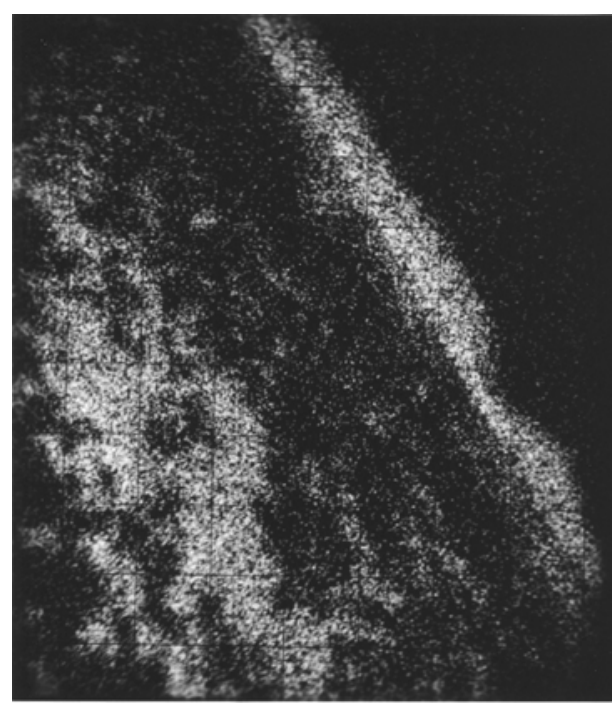

(g)

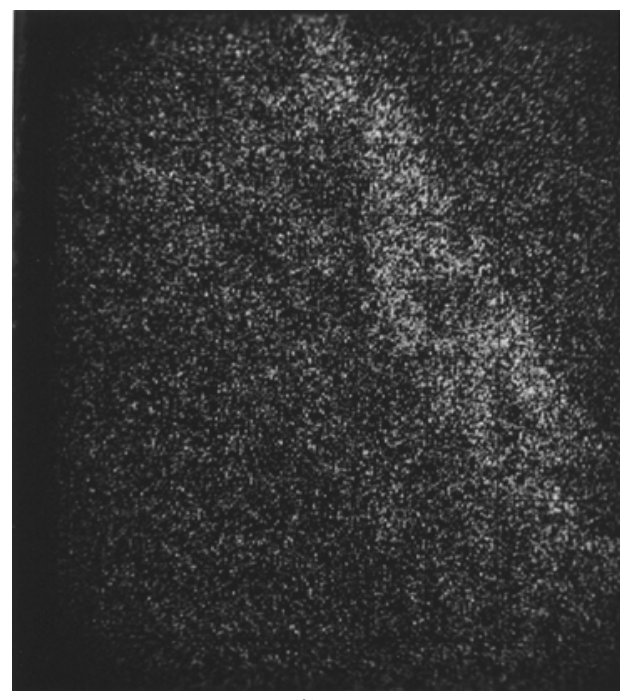

(i)

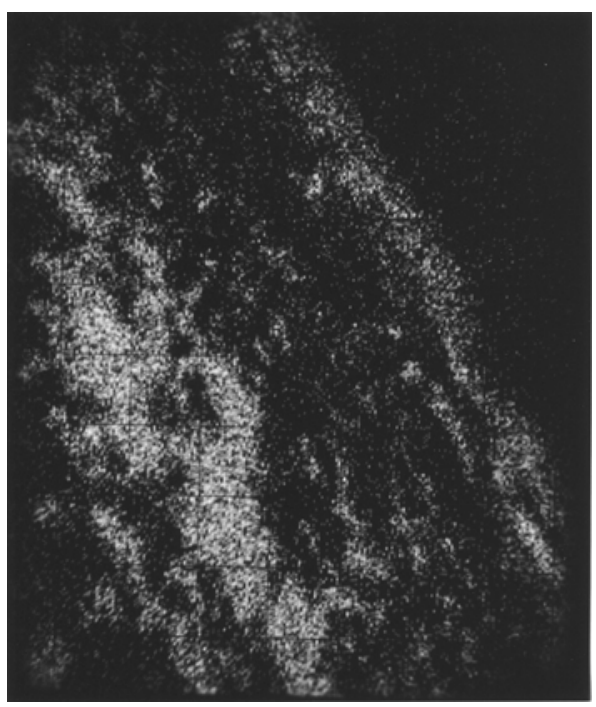

(h)

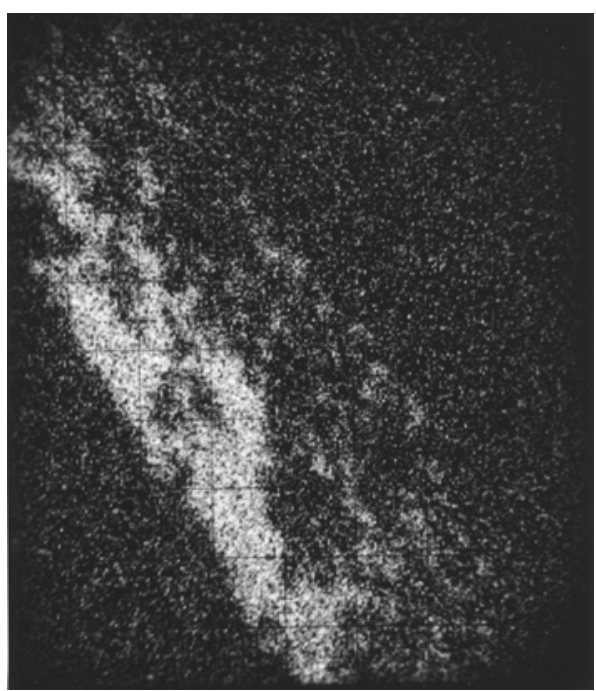

(j)

Fig. 3. (a) Electron Microprobe Specimen Current Image and X-ray Maps for (b) U, (c) Pu, (d) Zr, (e) Fe, (f) Cr, (g) Ce, (h) Nd, (i) Ru, and (j) Pd

Figure 4 shows an EPMA elemental trace taken at the fuel-cladding interface in DP16. The approximate original cladding boundary corresponds to where the $\mathrm{Cr}$ concentration drops to near zero. The elemental trace shows the same behavior for $\mathrm{Fe}, \mathrm{Cr}, \mathrm{U}, \mathrm{Pu}, \mathrm{Zr}, \mathrm{Ce}$, and $\mathrm{Nd}$ compared to what is observed with X-ray maps. The lanthanides penetrated the furthest into the cladding (approximately $40 \mu \mathrm{m}$ ) of any components originating in the fuel. 


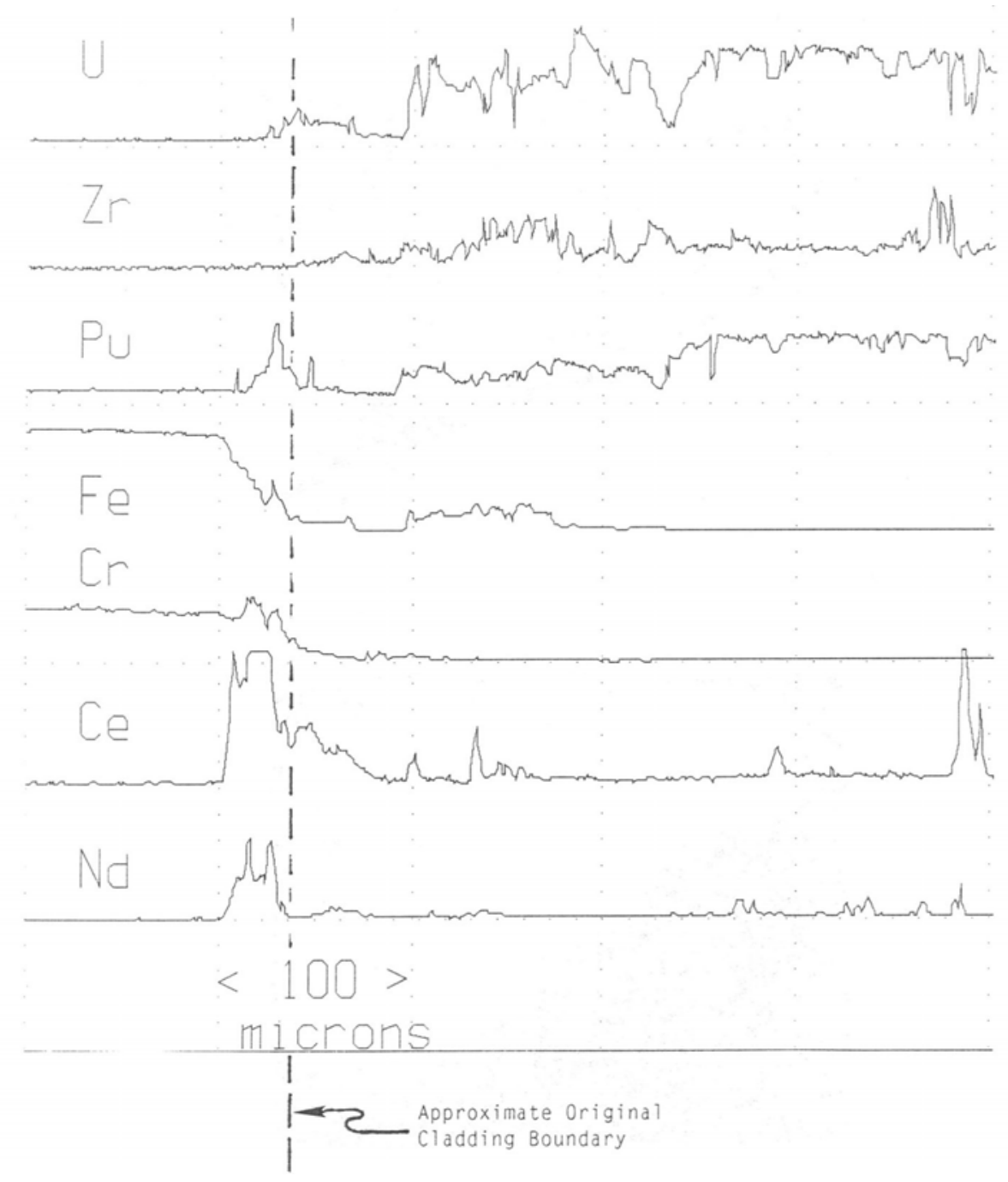

Fig. 4. Relative EPMA Concentration Profiles for U, Zr, Pu, $\mathrm{Fe}, \mathrm{Cr}, \mathrm{Ce}$, and Nd Across the Fuel-Cladding Interface for DP16

SEM/EDS analysis was completed on a sample from DP16 from axial elevation $\mathrm{x} / \mathrm{L}=0.84$. The local burn-up was determined to be 9.7 at\%, and the peak inner-cladding temperature (PICT) was $542^{\circ} \mathrm{C}$. The sample is shown in Fig. 5; to minimize dead time during EDS analysis and exposure to the machine operator, only a small section of cladding (approximately $20 \%$ of the size of the original) and adventitious fuel were analyzed. Analyses were completed at the left (a) and right (b) sides of the boxed area of the sample shown in Fig. 5. Figure 6 shows higher magnification SEM secondary and backscattered electron micrographs of interaction layers from the area to the left that was analyzed. Individual layers can be observed in this figure, and they have been labeled 1 through 4. 


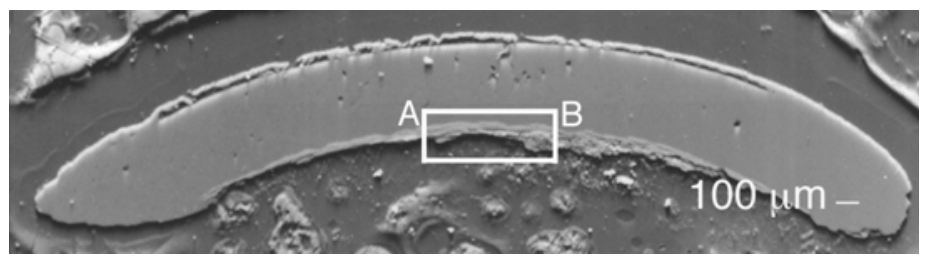

(a)

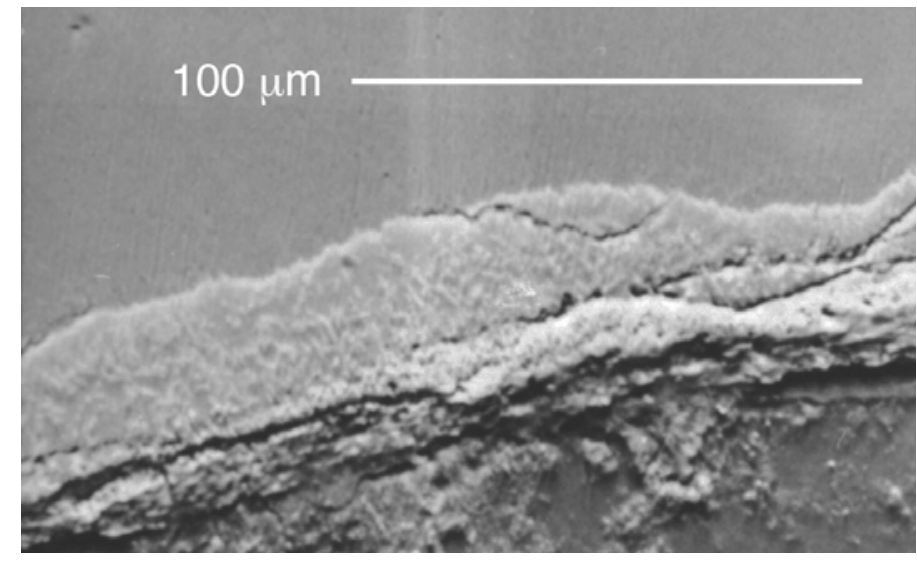

(b

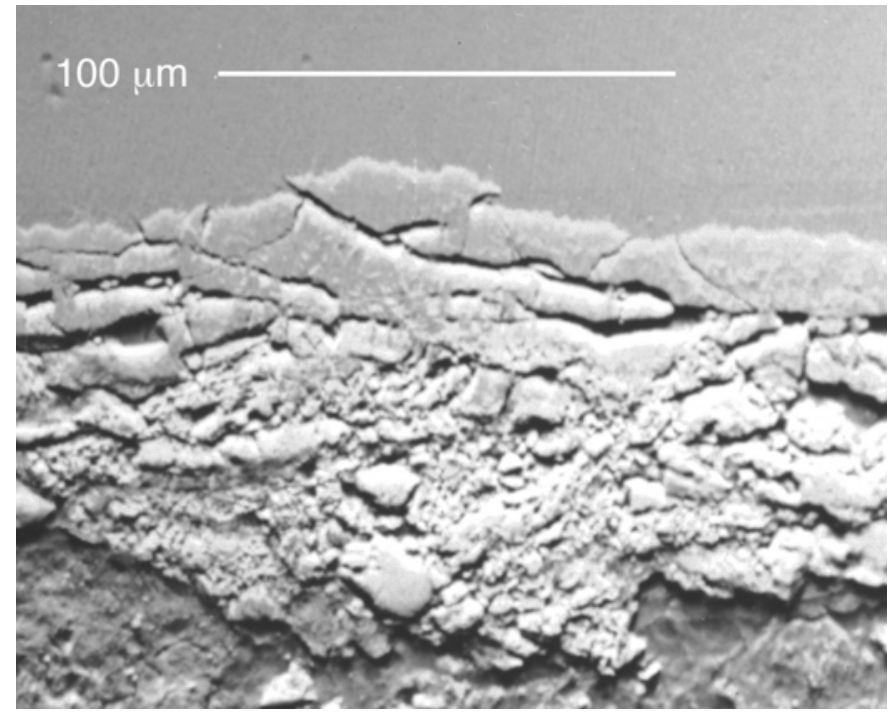

(c)

Fig. 5. Secondary Electron Micrographs of a Cladding Sample Taken from DP-16 (approximately $20 \%$ of the cladding remains from the original sample, prior to sample preparation, the fuel had been attached to the bottom of the sample) (a) Low Magnification Image of the Sample, and the Outlined Box Identifies the Region Where Subsequent Analyses were Focused, Specifically at Locations A and B, (b) Shows a Higher Magnification Image of Region A and (c) Shows Region B 


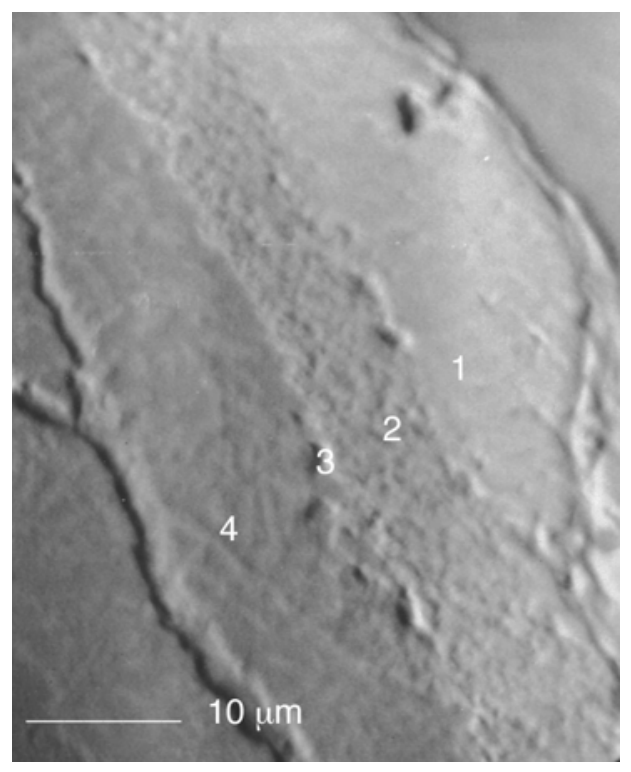

(a)

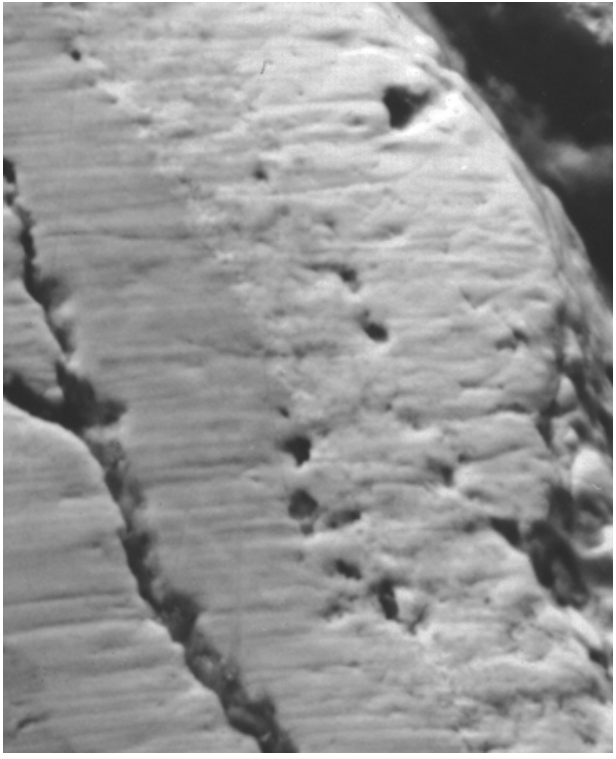

(b)

Fig. 6. Backscattered Electron (a) and Secondary Electron (b) Images of the Interaction Layers Observed in Location A for the Sample Taken from DP16 (the lower left is un-reacted cladding, and the upper right is mount material)

Table 3 enumerates the approximate compositions of the four phase layers, based on point-topoint SEM/EDS measurements taken in the various phase layers at location A. A composition profile through layers 1-4 is shown in Fig. 7 where spot readings were matched with a distance through the interaction zone (some constituent concentrations are grouped together). Layer 1 appears to consist of two phases and it contains the only Zr found in the sample and appreciable Pd. Only trace amounts of Fe and Cr were observed in Layer 1, and relatively high levels of lanthanide fission products were observed (about 50 at\% over the width of the layer).

Table 3. Approximate Compositions of Spot Readings Taken in Different Regions of the Phase Layers at Location A of DP16 SEM Sample (in at\%) ${ }^{\mathrm{a}}$

\begin{tabular}{|c|c|c|c|c|c|c|c|c|l|}
\hline Layer & Fe & Cr & Si & Pd & $\mathrm{Ce}^{\mathrm{b}}$ & $\mathrm{Nd}$ & $\mathrm{Zr}$ & $\mathrm{Pu}$ & \multicolumn{1}{|c|}{ Other } \\
\hline \hline 1 & 2 & 2 & 0 & 24 & 16 & 34 & 19 & 1 & - \\
\hline 1 & 1 & 1 & 5 & 35 & 19 & 33 & 5 & 1 & - \\
\hline 1 & - & - & 5 & 38 & 13 & 26 & 7 & 2 & 9La \\
\hline 1 & - & - & - & 20 & 10 & 16 & 31 & - & 6La,17Pb \\
\hline 2 & - & 34 & 6 & - & 11 & 23 & - & - & $\begin{array}{l}\text { 3Mo,6La, } \\
\text { 8U,9Sn }\end{array}$ \\
\hline 2 & 2 & 28 & 7 & - & 16 & 28 & - & - & $\begin{array}{l}\text { La,7U, } \\
1 \text { Ag, 10Sn }\end{array}$ \\
\hline
\end{tabular}


Table 3. (Contd.)

\begin{tabular}{|c|c|c|c|c|c|c|c|c|l|}
\hline Layer & $\mathrm{Fe}$ & $\mathrm{Cr}$ & $\mathrm{Si}$ & $\mathrm{Pd}$ & $\mathrm{Ce}^{\mathrm{a}}$ & $\mathrm{Nd}$ & $\mathrm{Zr}$ & $\mathrm{Pu}$ & Other \\
\hline \hline 3 & 28 & 20 & 5 & 15 & 10 & 12 & - & 11 & - \\
\hline 4 & 63 & 10 & 4 & - & 7 & 13 & - & 0.3 & $1 \mathrm{La}$ \\
\hline 4 & 66 & 15 & 6 & - & 5 & 7 & - & 0.2 & $1 \mathrm{Ag}$ \\
\hline 4 & 67 & 13 & 6 & - & 5 & 7 & - & 0.2 & $1 \mathrm{Ag}$ \\
\hline 4 & 69 & 16 & 4 & - & 5 & 5 & - & 0.3 & $1 \mathrm{Ag}$ \\
\hline
\end{tabular}

a. Nominal un-reacted cladding had composition of 84Fe-12Cr-2Si-1Mn-0.4Ni for components listed in Table 3 (determined by SEM/EDS).

b. It is difficult to resolve lanthanides using SEM/EDS due to peak overlap. As a result, the numbers given for $\mathrm{Ce}$ and $\mathrm{Nd}$ should be taken as qualitative numbers, and in some cases La may be present with the Ce and Nd (based on EPMA X-ray maps).

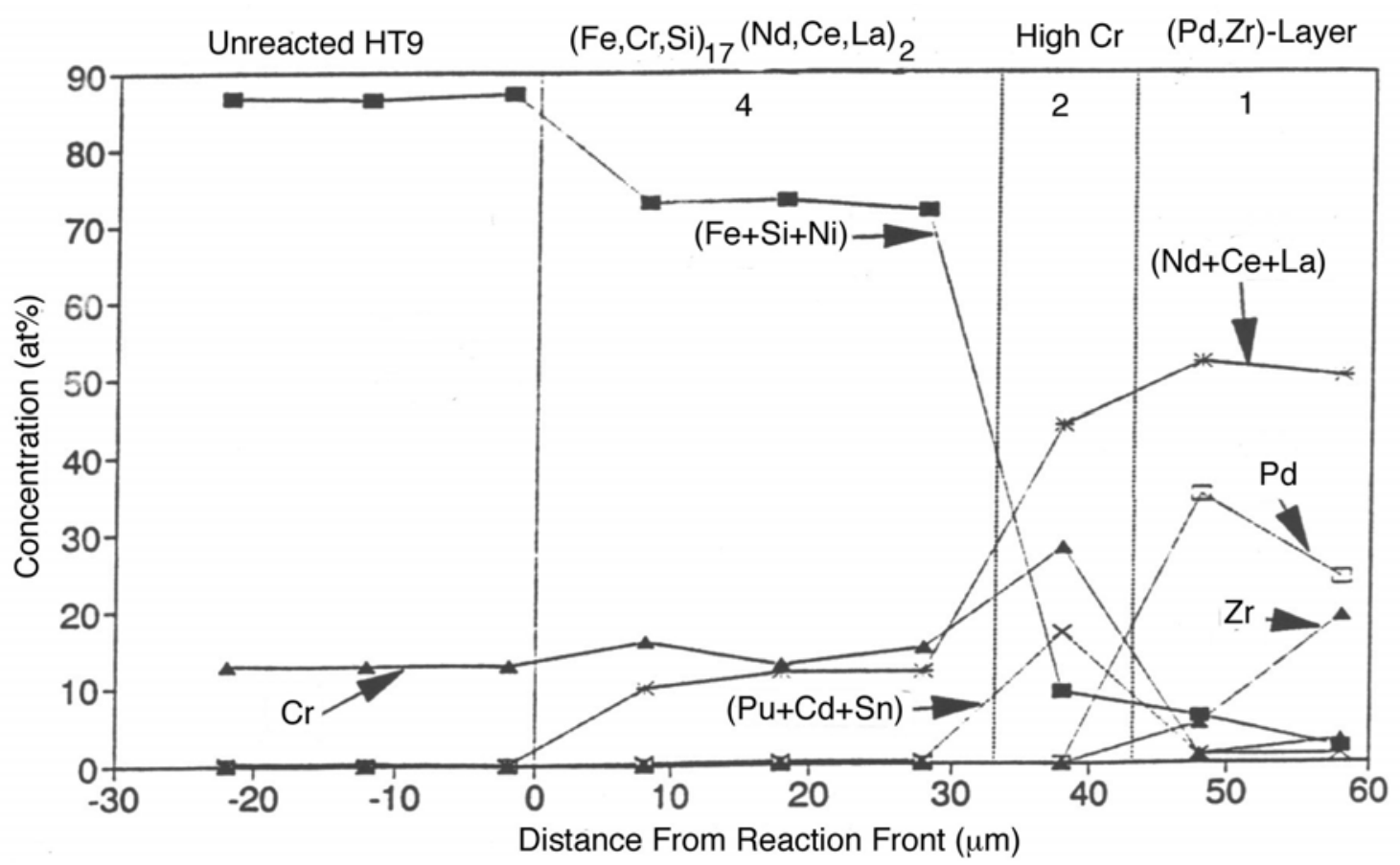

Fig. 7. Measured Compositions as a Function of Linear Position in Location A (the values are compiled in Table 3, the numbers at the top correspond to the layer numbers in Table 3)

Layer 2 contained lanthanides and relatively high levels of Cr. A relatively high level of $\mathrm{U}$ was observed in this layer, which agrees with EPMA data where $U$ does penetrate into the cladding. The detection of Sn in layer 2 seems believable and has been seen in other samples analyzed with EPMA.

Layer 3 was a very thin layer (approximately $1 \mu \mathrm{m}$ wide), and as a result was hard to differentiate from layer 2 (Fig. 6). Composition differences were detected between layers 2 and 3.15 at\% Pd, 
28 at\% Fe, and 11 at\% Pu concentrations were detected in layer 3. The fact that layer 2 had negligible levels of Fe, $\mathrm{Pd}$, and Pu while notable concentrations of these elements are observed in layer 3 demonstrates that layer 3 is an actual phase layer. The Pu in layer 3 is evidence of the furthest penetration of any non-fission product fuel constituent.

Layer 4 was the widest layer $(20-28 \mu \mathrm{m})$ at location A. A fine second phase was observed dispersed throughout this layer. The compositions reported in Table 3 for this layer correspond to a combination of the dispersed and matrix phases. 10-12 at\% of lanthanides is observed in layer 4. Why this layer may be associated with the $(\mathrm{Fe}, \mathrm{Cr}, \mathrm{Si})_{17}(\mathrm{Nd}, \mathrm{Ce}, \mathrm{La})_{2}$ phase will be discussed later.

The second region of the sample where composition information was determined for the layers was at the right-side of the boxed area of the sample shown in Fig. 5 (location B). An SEM micrograph of the area analyzed is presented in Fig. 8. The layers were labeled 1-4 and layer 4 had a composition very near that of the phase labeled layer 4 at location A. The compositions observed for spot readings taken in layers 1-4 are depicted in Table 4.

Table 4. Approximate Compositions of Spot Readings of Phase

Layers at Location B of DP16 SEM Sample (in at\%)

\begin{tabular}{|c|r|r|r|r|r|r|r|r|l|l|}
\hline Layer & $\mathrm{Fe}$ & $\mathrm{Cr}$ & $\mathrm{Mo}$ & $\mathrm{Si}$ & $\mathrm{Pu}$ & $\mathrm{U}$ & $\mathrm{Ce}$ & $\mathrm{Nd}$ & $\mathrm{La}$ & \multicolumn{1}{|c|}{ Other } \\
\hline \hline 1 & 41 & - & - & 2 & 15 & - & 10 & 21 & 4 & $7 \mathrm{Pd}$ \\
\hline 1 & 66 & 2 & - & 7 & 22 & - & 2 & 2 & 2 & $1 \mathrm{Ni}, 1 \mathrm{Ba}$ \\
\hline 1 & 55 & 14 & 0.4 & 2 & 3 & 1 & 7 & 15 & 2 & $0.4 \mathrm{Ni}$ \\
\hline 2 & - & 28 & 1 & - & 5 & 4 & 15 & 39 & 6 & - \\
\hline 3 & 37 & 39 & 2 & 2 & 8 & 2 & 5 & 3 & 1 & $0.5 \mathrm{Mn}$ \\
\hline 4 & 69 & 17 & - & 1 & 0.2 & - & 5 & 6 & - & $1 \mathrm{Mn}, 0.4 \mathrm{Ni}$ \\
\hline
\end{tabular}




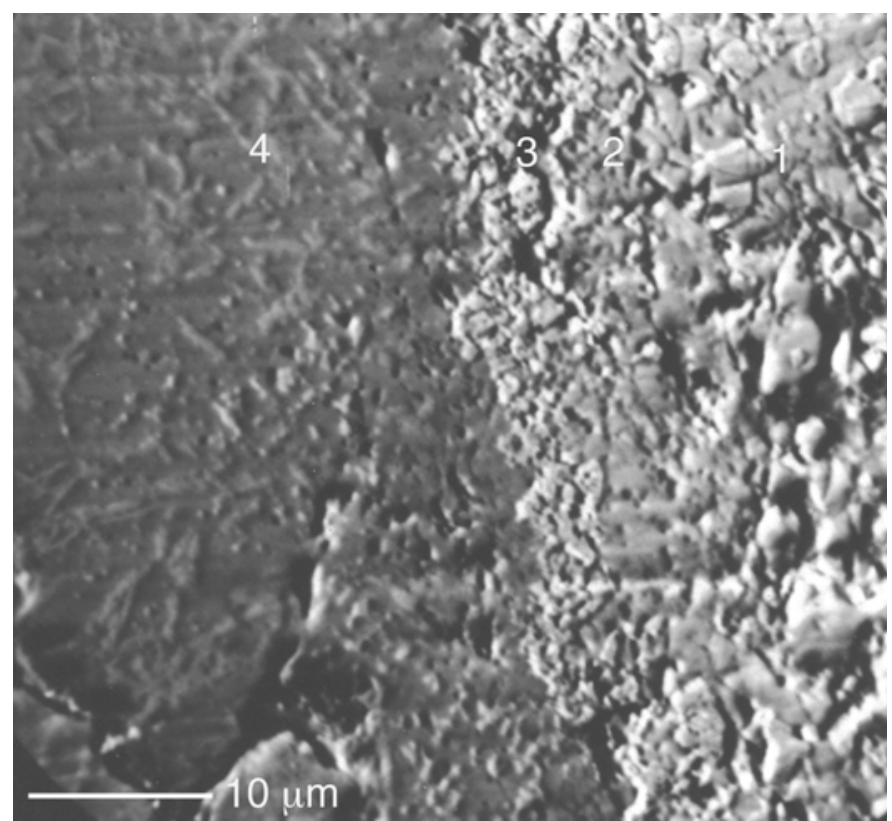

(a)

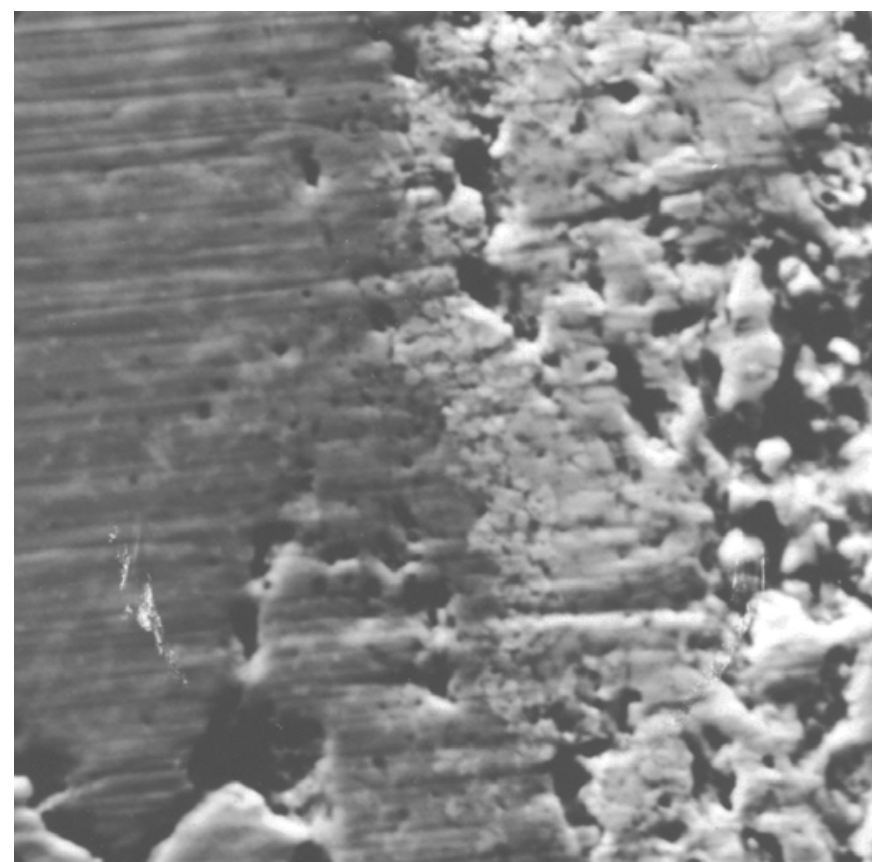

(b)

Fig. 8. Backscattered Electron (a) and Secondary Electron (b) Images of the Interaction Layers Observed in Location B for the Sample Taken from DP16 (the layer to the far left is the same as layer 4 in Fig. 6)

Layer 1 appeared to contain different types of fine phases and was not a well-defined layer. The first measurement in Table 3 for layer 1 is for an average area near layer 2. The phase or phases 
in this area contain 35 at\% lanthanides, 41 at\% Fe, 7 at\% Pd, and 15 at\% Pu. Two other areas where spot readings were taken had different compositions. The second measurement listed in Table 3 was for a small particle (about $5 \mu \mathrm{m}$ diameter) further into the fuel, and the final measurement in layer 1 was taken at the furthest location in the fuel available, and it contained more lanthanides and less Pu than did the second measurement.

Layer 2 contained approximately 60 at\% lanthanides, 28 at\% $\mathrm{Cr}$, and 9 at\% U plus Pu and was similar in composition and size to the layer 2 shown in Fig. 6. The major difference between the two layers was that the layer 2 in Fig. 6 had Cd and Sn, while layer 2 in Fig. 8 had U and Pu. If in fact the Cd observed at location B is mainly $U$ (possibly due to overlap of the EDS peaks), then the layers at both locations are even more similar.

Layer 3 was approximately $1 \mu \mathrm{m}$ wide and contained relatively high amounts of Cr (39 at\%) and actinides (10 at\% $\mathrm{U}$ plus $\mathrm{Pu}$ ). The Fe content was higher and the lanthanide content was lower for this layer 3 compared to the layer 3 in Fig. 6.

The layer nearest the un-reacted cladding, layer 4, consisted of two-phases, as did the layer 4 in Fig. 6. Yet, in Fig. 8 the precipitate phase appeared slightly larger in layer 4 than it did in the layer 4 in Fig. 6 . As a result, attempts were made to determine the concentration of the precipitate phase. The composition listed in Table 3 for layer 4 is the average composition for the matrix and precipitate phase together. SEM/EDS analysis of the precipitate phase suggested that the precipitate phase was lower in Fe (67 at\% compared to 72 at\%) and $\mathrm{Cr}$ (12 at\% compared to 17 at\%) and had about twice as much lanthanides (15 at\% compared to 8 at\%) compared to the matrix phase.

\subsubsection{DP21}

DP21 is another HT9 clad fuel element with U-Pu-Zr alloy fuel that is of particular interest, because of its relatively high burn-up of approximately 11.4 at\%. DP21 was run as part of the same fuel assembly as DP16. It exhibited the same major features as were described for DP16. The buildup of lanthanides at the fuel-cladding interface was notable, and these lanthanides combined with $\mathrm{Fe}$ and $\mathrm{Ni}$ from the cladding to form phases. The main features of the fuel-cladding interaction zones observed in DP16 and DP21 are representative of the smaller amounts of fuelcladding interaction observed for fuel element T459-a fuel element irradiated to only 3 at\%.

\subsubsection{HT9-Clad Elements with Binary U-Zr Alloy Fuel}

\subsubsection{DP11}

DP11 was a fuel element with U-23at\% Zr fuel that was destructively analyzed to investigate the interaction between the fuel and cladding. This fuel element was irradiated to about 10 at\% burnup at elevated cladding temperatures (630 to $660^{\circ} \mathrm{C}$ BOL temperature). A specimen was taken from an axial position 14.75 inches from the bottom of the pin and analyzed using EPMA. Figure 9 shows an elemental trace through a region of fuel-cladding interaction zone. The vertical scale in this trace is uncorrected X-ray intensity, and the x scale is position (the cladding is to the left) with the cladding inner diameter (ID) location being taken as zero. At this particular location, there is a $50 \mu \mathrm{m}$ wide zone of the cladding that is high in $\mathrm{Cr}$ and low in $\mathrm{Fe}$ and $\mathrm{Ni}$. $\mathrm{Ni}$ is 
also depleted from the cladding for another $40 \mu \mathrm{m}$ into the cladding over what is observed for the Fe. Into the fuel, Fe has interdiffused around $250 \mu \mathrm{m}$ and the $\mathrm{Ni}$ around $20 \mu \mathrm{m}$. In the $50 \mu \mathrm{m}$ wide band in the cladding with high $\mathrm{Cr}$ and low $\mathrm{Fe}$ and $\mathrm{Ni}$, lanthanide concentrations are elevated. Ce and Nd are the principal elements in this layer and lower levels of La, Pr, and Sm are also observed. A possible presence of Pd in the fuel-cladding interaction zone is observed, based on X-ray maps. Figure 10 shows typical X-ray maps taken to identify the locations of the various components at the fuel-cladding interface. 


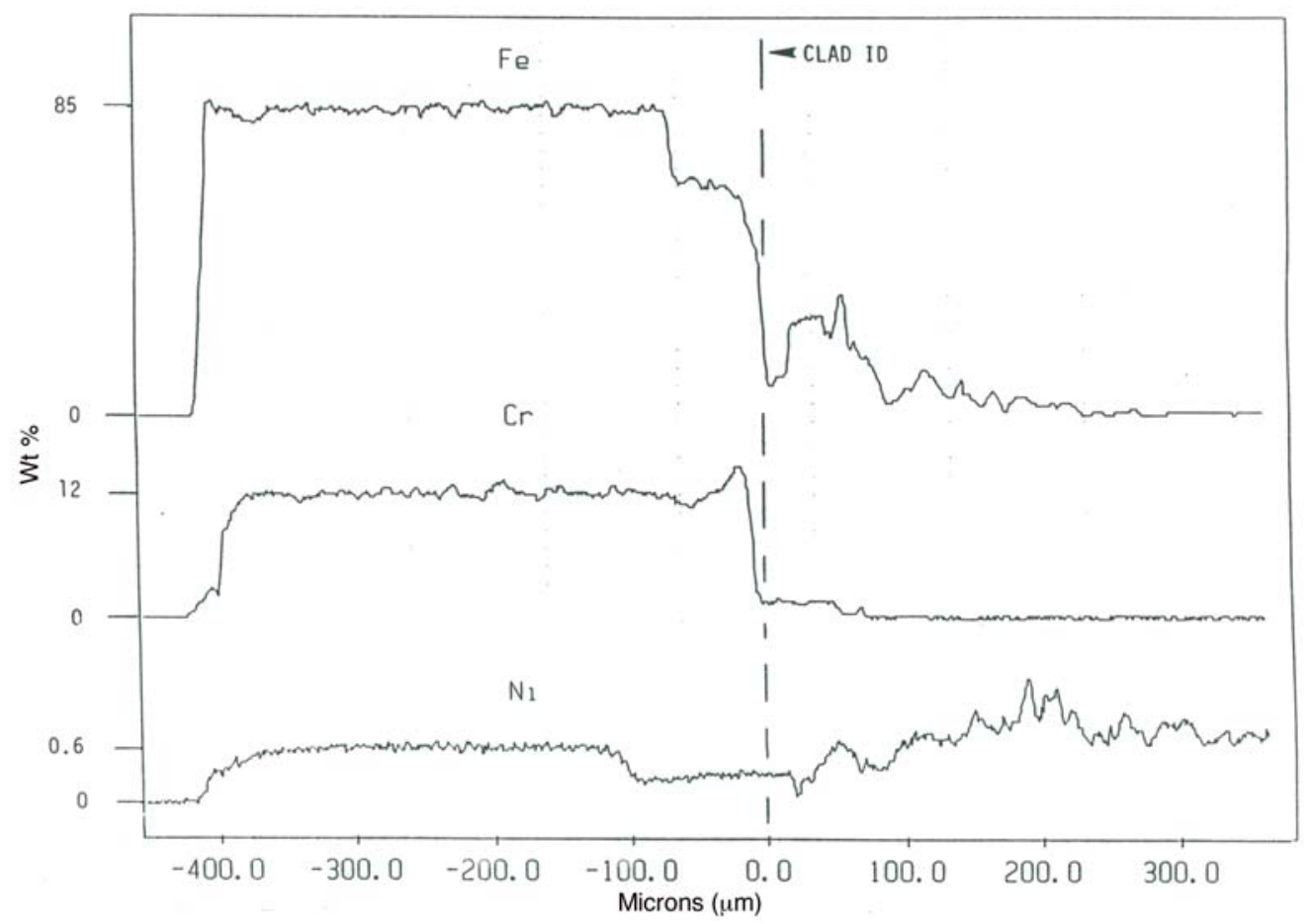

(a)

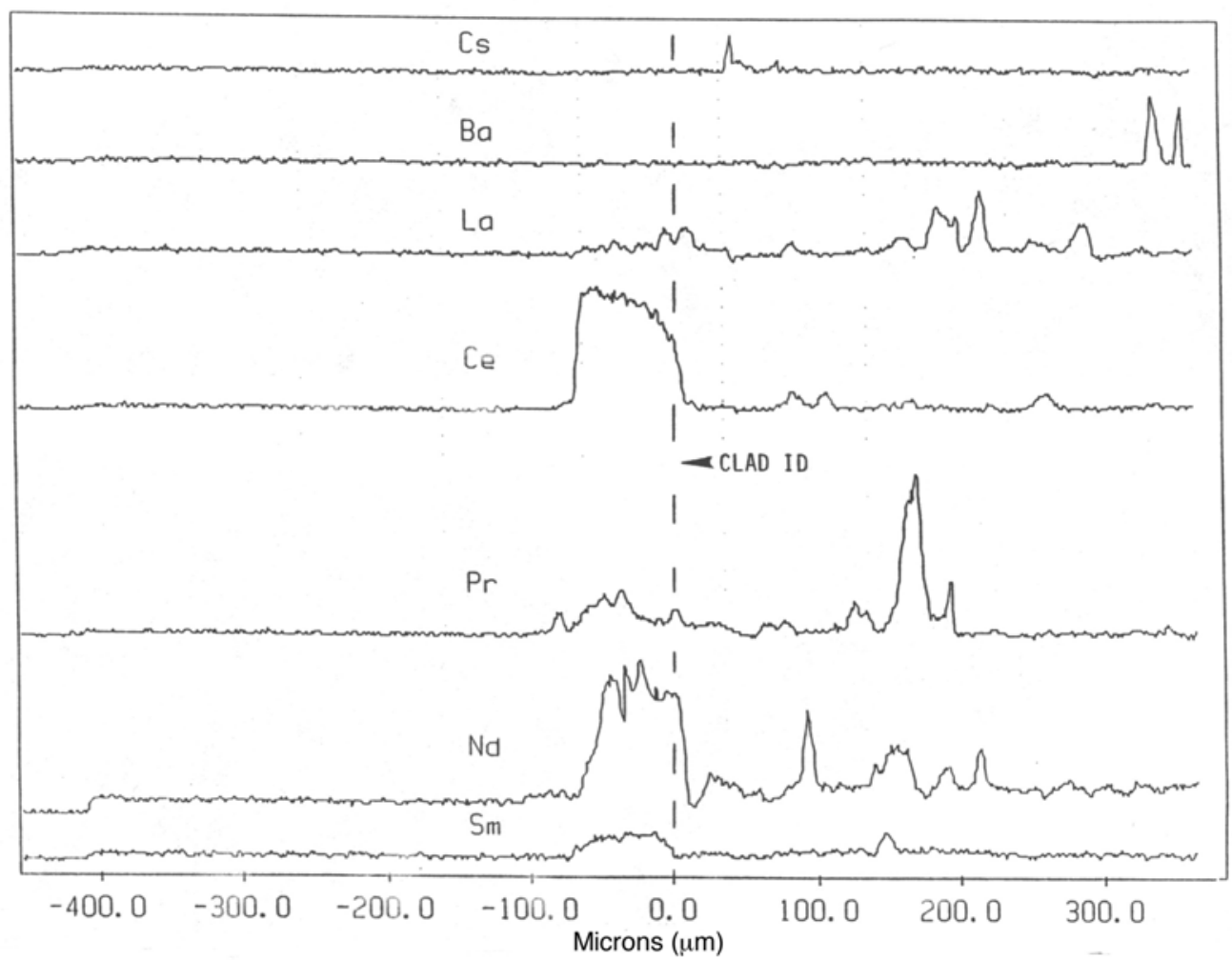

(b)

Fig. 9. Measured Compositions as a Function of Linear Position in Location A (a) Shows Elemental Traces for Cladding Constituents and (b) Shows Traces for the Fission Products 


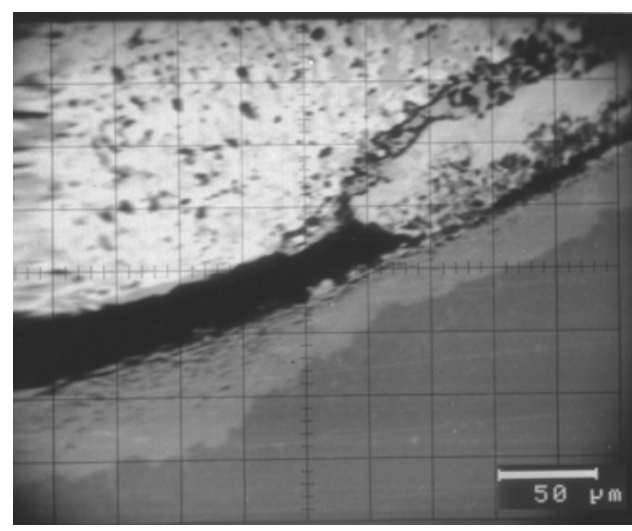

(a)

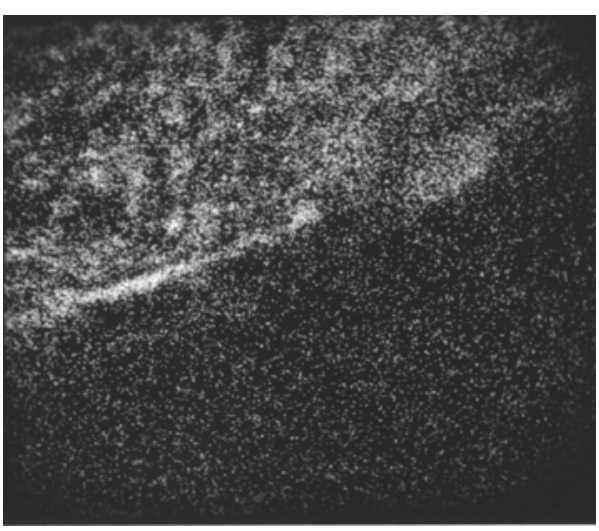

(c)

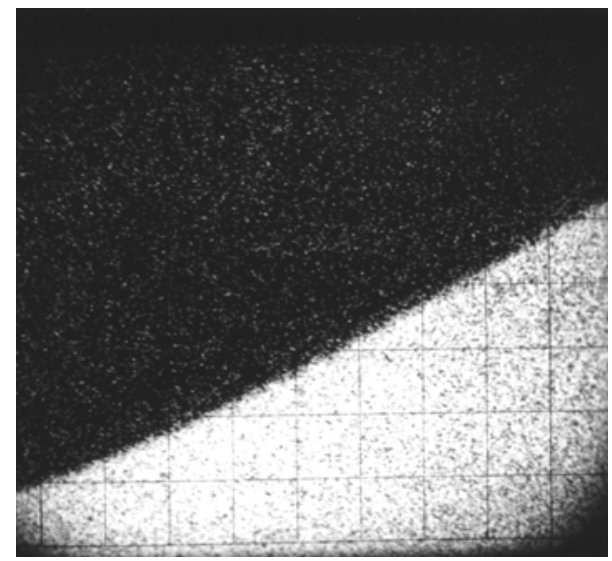

(e)

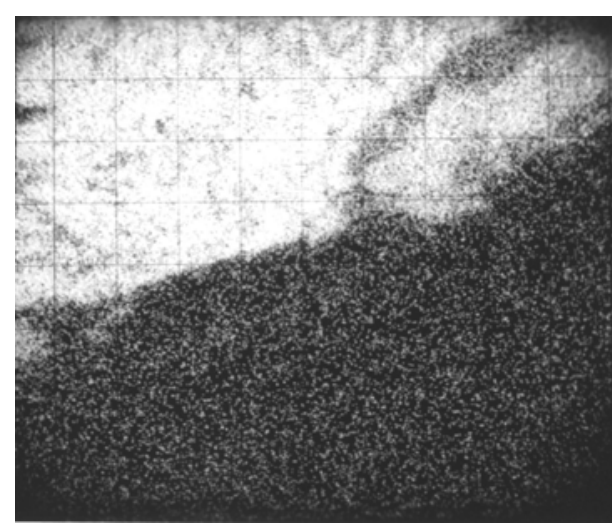

(b)

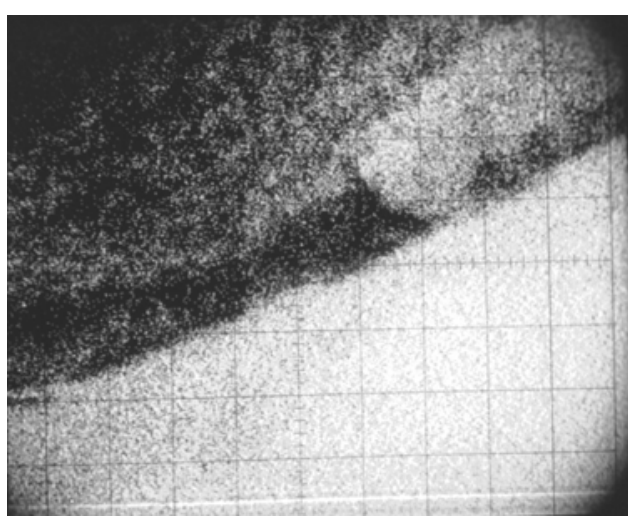

(d)

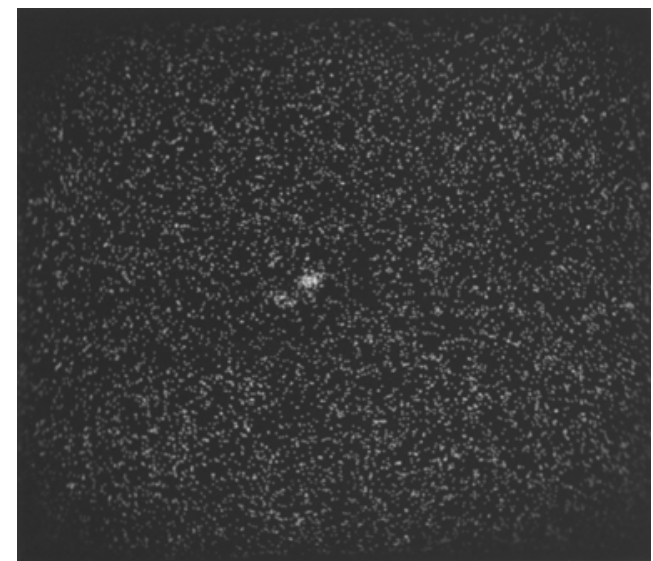

(f) 


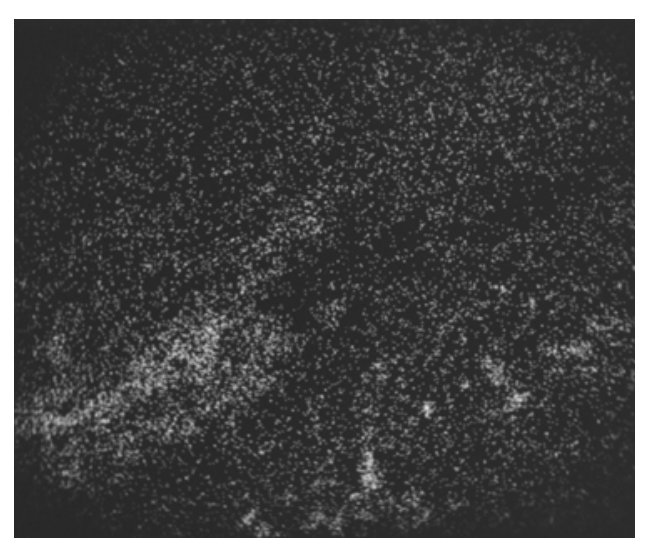

(g)

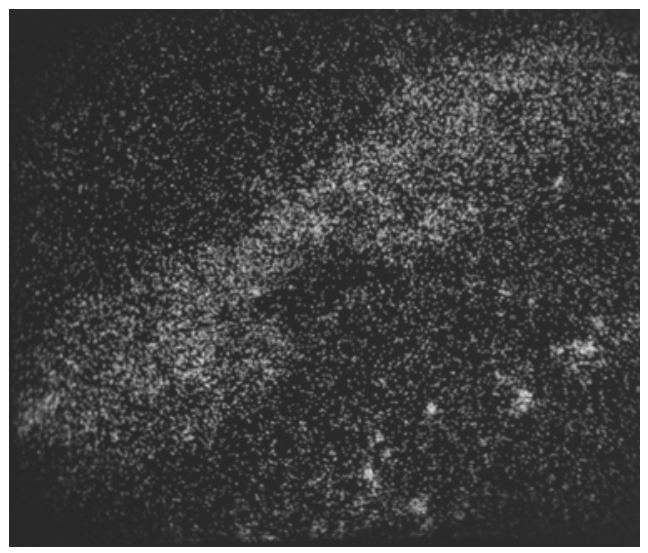

(i)

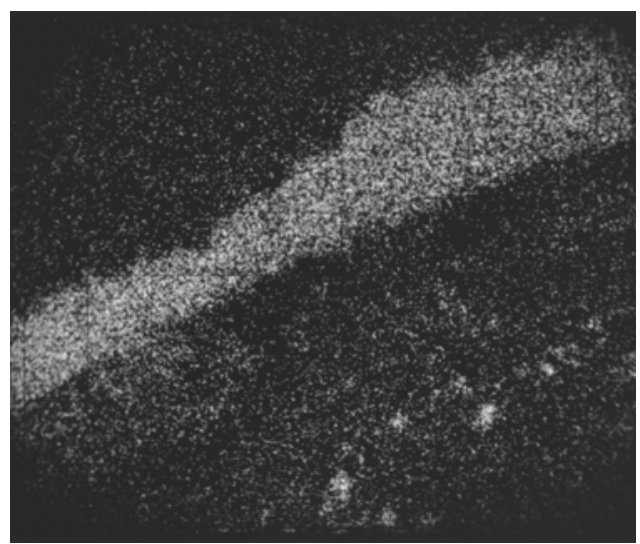

(h)

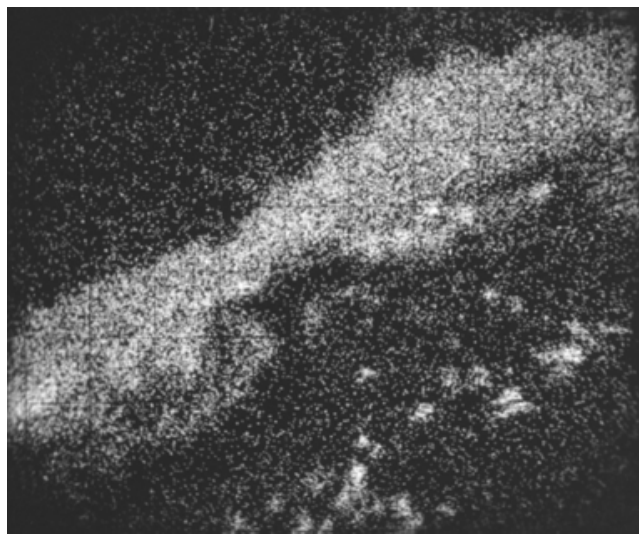

(j)

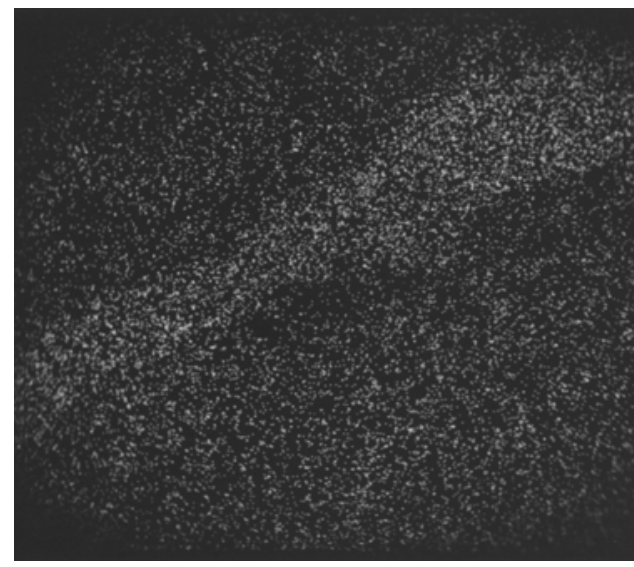

(k)

Fig. 10. (a) Electron Microprobe Specimen Current Image and X-ray Maps for (b) U, (c) Zr, (d) Fe, (e) Cr, (f) Ba, (g) La, (h) Ce, (i) Pr, (j) Nd, and (k) Sm 


\subsubsection{DP81}

Two specimens were examined from fuel element DP81, an element with U-23Zr fuel and HT9 cladding and irradiated to 5 at\% burn-up. Samples were cut from positions 0.75 in. and 3.125 in. from the top of the fuel element. Fuel-cladding interaction was observed in the sample taken at 0.75 in. but not in the sample taken at 3.125 in. from the top of the element. Based on the praseodymium penetration into the cladding, the fuel-cladding interaction zone is $70 \mu \mathrm{m}$ wide. An $80 \mu \mathrm{m}$ wide band of the cladding was Ni-depleted. Fission product constituents that penetrated into the cladding included $\mathrm{Ce}, \mathrm{Pr}, \mathrm{Nd}, \mathrm{La}$, and $\mathrm{Sm}$. Besides a high atomic number band, a band was also detected where grain boundary penetration of fission products into the cladding had apparently occurred.

\subsubsection{Breached Fuel Elements}

Results from examinations of fuel elements that were kept in the reactor after failure of the cladding have been reported [6]. Failed elements DP75 and DP70 (U-10 wt\% Zr fuel and HT9 cladding) were analyzed and compared to un-failed elements DP04 and DP11, which had the same fuel and cladding. Brittle, non-uniform bands of lanthanides were observed to penetrate up to $170 \mu \mathrm{m}$ into the cladding in DP75, and up to $140 \mu \mathrm{m}$ into the cladding in DP70 (in the hottest regions of the fuel elements). A maximum of $90 \mu \mathrm{m}$ of lanthanide penetration was observed in the un-failed elements DP04 and DP11. The breached fuel elements were run to 10 at $\%$ burn-up, had a peak calculated cladding temperature near $660^{\circ} \mathrm{C}$, and had up to $45 \%$ of the total cladding thickness of $5.84 \mathrm{~mm}$ consumed by interaction layers. The un-breached fuel elements exposed to the same conditions had only $20 \%$ of the cladding consumed by layers. Carbon depletion zones (up to approximately $60 \mu \mathrm{m}$ thick) were observed on the cladding side of the interaction layers.

\subsection{Layers in Fuel Elements with D9 or Type 316 Stainless Steel Cladding}

D9 and Type 316 stainless steel are austenitic steels that contain appreciable nickel. Those fuel elements clad with these materials imparted slight differences in their observed fuel-cladding interaction compared to the elements clad with the martensitic (low Ni) stainless steel HT9. The fuel element T341 was the only element with Type 316 stainless steel cladding that was analyzed to investigate fuel-cladding interaction. Due to its low burn-up of 0.4 at\%, negligible fuel-cladding interaction was observed. The fuel elements discussed in the context of fuel-cladding interaction will be the ones clad with D9 stainless steel. The major differences between D9 and Type 316 stainless steel is that D9 has more Ni, less $\mathrm{Cr}$, and it contains Ti (Table 1).

\subsubsection{D9-Clad Elements with Ternary U-Pu-Zr Alloy Fuel}

\subsubsection{T106}

Fuel element T106 had U-16Pu-23Zr fuel and D9 cladding and was irradiated to 17 at\% burn-up. The EPMA analysis of T106 investigated the development of fuel-cladding interaction layers, along with the distribution of noble metal fission products in discrete phases in the outer periphery of the fuel at two different locations in a longitudinally-cut sample. Presented in Fig. 11 is an optical micrograph of the fission product-containing phases that were observed at one location in T106. One observed phase was a blocky particle observed throughout the fuel. 
X-ray maps taken of the T106 specimen showed that $\mathrm{Zr}, \mathrm{Ru}, \mathrm{Pd}$, and $\mathrm{Ni}$ comprised these particles. Another type of observed phase was an irregular-shaped, gray phase that developed in the outer regions of the fuel. Light and dark regions were observed in this type of phase and Table 5 enumerates some measured compositions of light and dark phase regions. Compositions varied widely from point to point in both the light and dark gray phases. Small particles containing $\mathrm{Ba}$ and Te were also observed along with the light and dark gray phases.

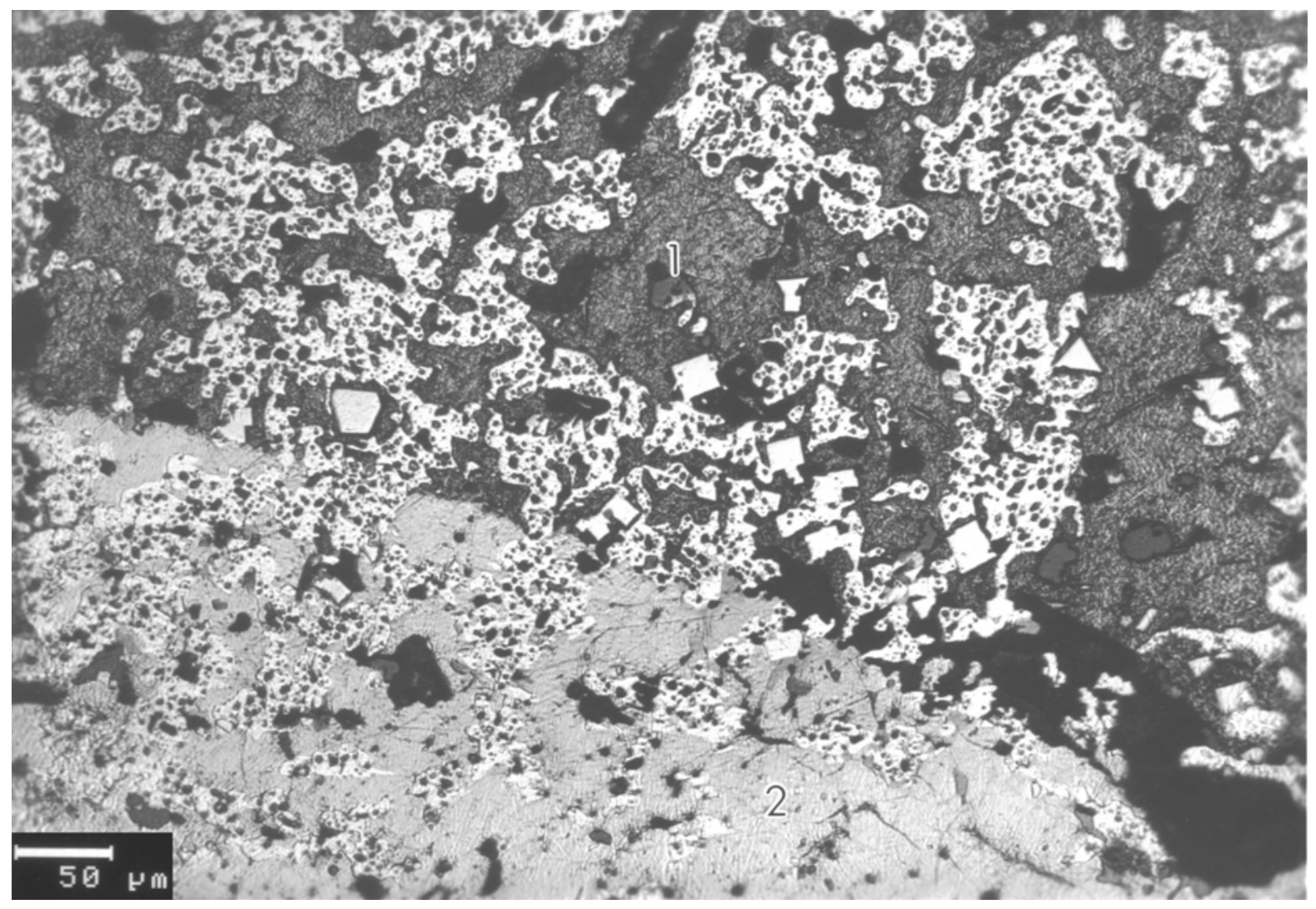

Fig. 11. Optical Micrograph of an Area Near the Fuel-Cladding Interface Where Dark-Gray Precipitates (1) and Light-Gray Precipitates (2) are Observed (the blocky particles are enriched in $\mathrm{Zr}, \mathrm{Ru}, \mathrm{Pd}$, and $\mathrm{Ni}$ )

Table 5. Approximate Compositions of Light and Dark Regions of Noble Metal-Containing Phases in a Sample From Fuel Element T106 (in at\%)

\begin{tabular}{|c|c|c|c|c|c|c|c|c|}
\hline Region & $\mathrm{U}$ & $\mathrm{Pu}$ & $\mathrm{Zr}$ & $\mathrm{Pd}$ & $\mathrm{La}$ & $\mathrm{Ce}$ & $\mathrm{Pr}$ & $\mathrm{Nd}$ \\
\hline \hline Light Gray & 1.2 & 1.9 & 0.3 & 20.2 & 23.7 & 17.6 & 3.8 & 31.4 \\
\hline Dark Gray & 0 & 3.8 & 0 & 0 & 27.7 & 29.2 & 3.9 & 34.1 \\
\hline
\end{tabular}


At another location in the fuel (Fig. 12), blocky particles were observed and analyzed. These particles contained Zr, Mo, Tc, Ru, Rh, and Pd, based on X-ray maps. Nickel, which was observed in similar blocky particles in another area of the fuel, was not seen in these particles.

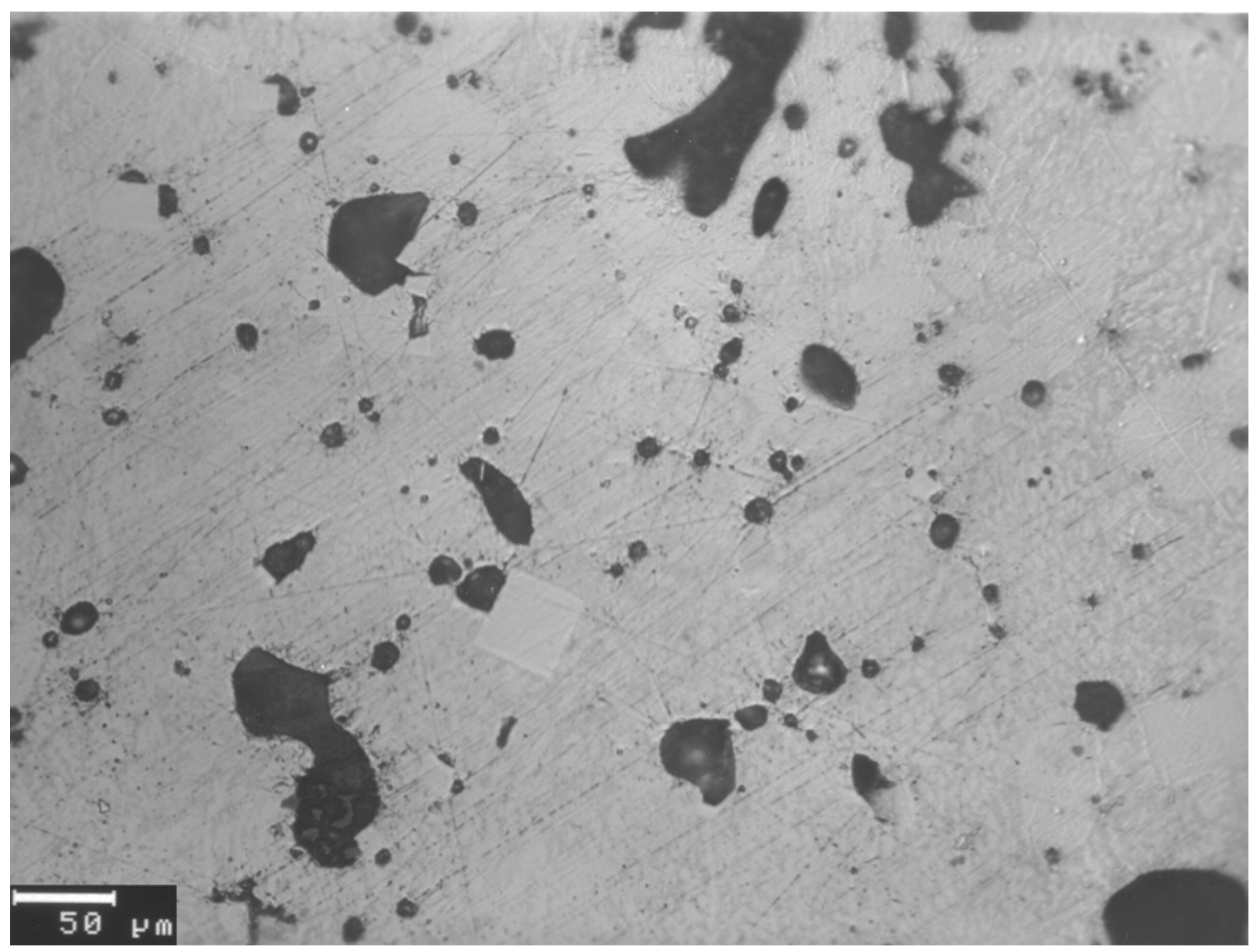

Fig. 12. Optical Micrograph Showing the Presence of Blocky Particles Near the Fuel-Cladding Interface

The fuel-cladding interaction zone itself in T106 was a fairly continuous band around the inner diameter of the cladding. About $20 \mu \mathrm{m}$ of interaction was observed in the analyzed sample, and it consisted of two layers. Element maps for the interaction zone showed that the $\mathrm{Fe}$ and $\mathrm{Cr}$ concentration levels are slightly enriched in the interaction zone, and the $\mathrm{Ni}$ is depleted. The interaction zone contained Ce, La, Pr, Nd, Pd, and Sn. Evidence of minor amounts of Pu in the interaction zone was additionally observed.

\subsubsection{T112}

Fuel element T112 had U-16Pu-23Zr fuel and D9 cladding and was irradiated to 11.9 at\% burnup. Metallographic specimens were taken from this element at locations 3.5, 7.5, 13.5, and 14.25 inches from the top of the element. The specimen taken at the hottest part of the pin (14.25 in.) exhibited the most fuel-cladding interaction (approximately $70 \mu \mathrm{m}$ ). Figure 13 shows the observed interaction layers in this region of the pin, along with the indentation marks left behind 
from hardness testing that was performed on the sample. The interaction zone and un-reacted cladding exhibited hardness values of approximately 1100 and $350 \mathrm{DPH}$, respectively. The interaction layers observed in the cladding of a sample taken from a position of 13.5 in. are presented in Fig. 14 (also note the light and dark contrast fission product phases that can be found in the outer periphery of the fuel). In Fig. 15, the fuel-cladding interface at an axial position of 3.5 is shown. An intact layer of Zr-rind, which is a thin layer on the outer surface of the fuel alloy that is produced during the injection casting of fuel using quartz molds, is apparent along with dark-contrast fission product phases that exist at the outer periphery of the fuel. No fuel-cladding interaction is observed where the $\mathrm{Zr}$-rind is intact.

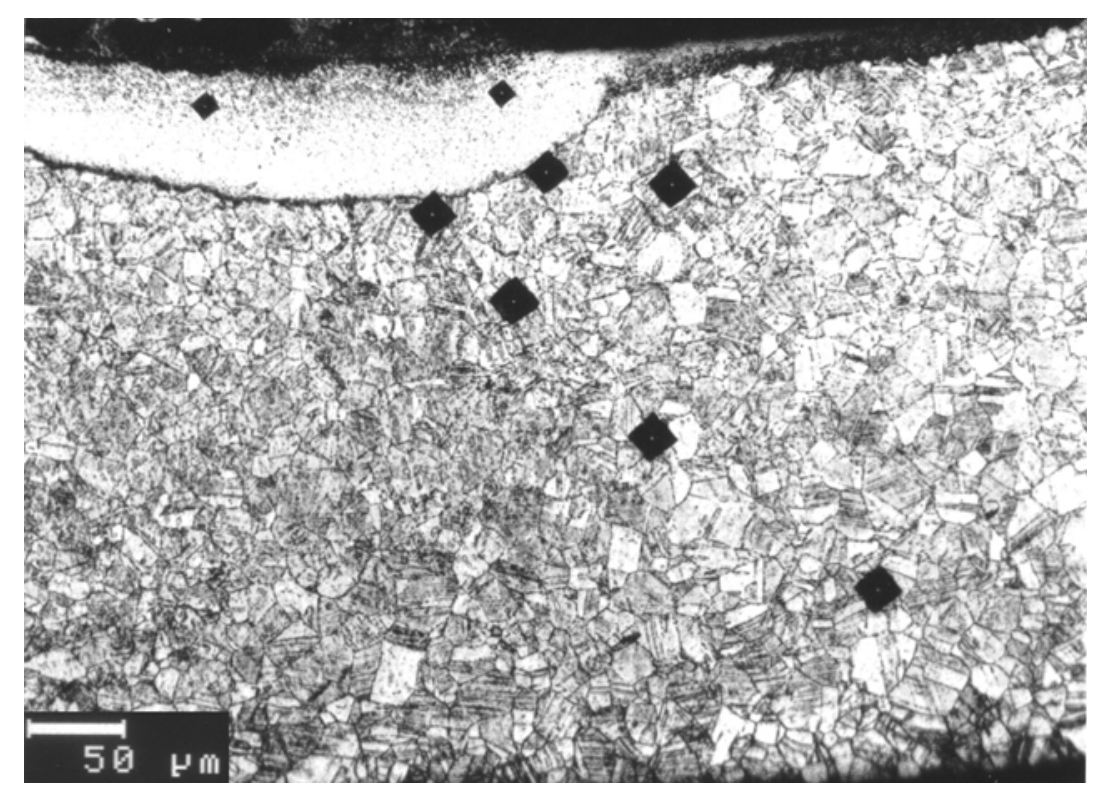

Fig. 13. Optical Micrograph Showing the Presence of an Interaction Zone at the Fuel-Cladding Interface (hardness indents reveal the increased hardness of the interaction zone vis-a-vis the un-reacted cladding) 


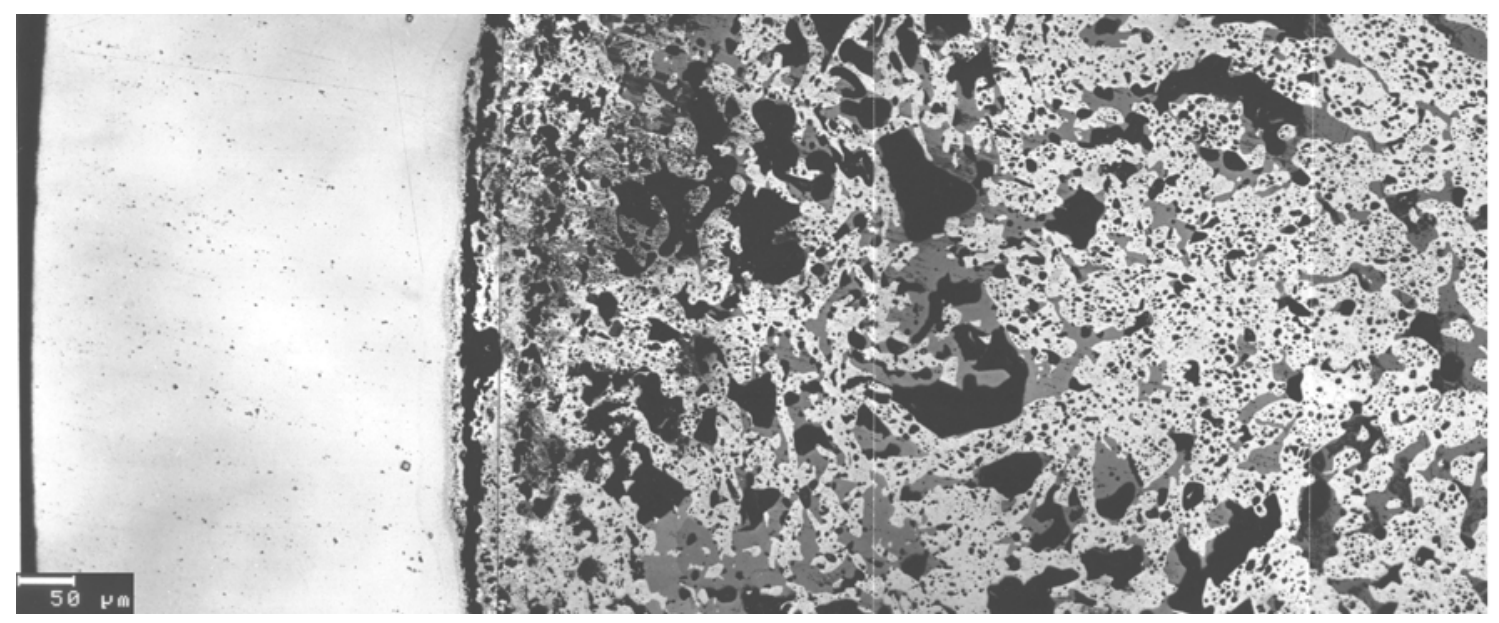

Fig. 14. Optical Micrograph Showing The Presence of a Fuel-cladding Interaction Zone and Large Quantities of Fission Products Filling Voids Near the Cladding

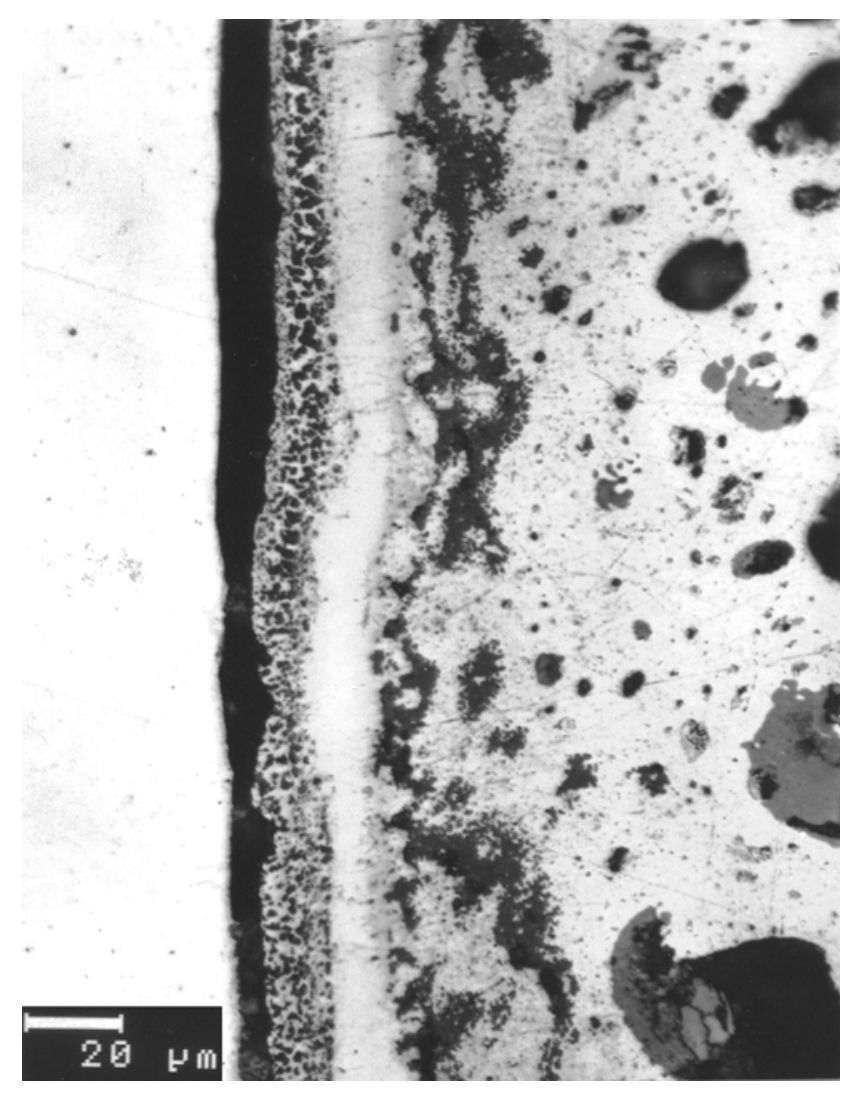

Fig. 15. Optical Micrograph Showing the Fuel-cladding Interface Near An Intact Zr-rind Layє 


\subsubsection{T087}

EPMA was performed on the D9-clad fuel element T087, which had U-16Pu-23Zr fuel and was irradiated to 10 at\% burn-up. In addition to the original fuel and cladding components, the fission products Tc, Pd, Cs, Ba, La, Ce, Pr, Nd, Sm, Eu, and Gd were detected in the fuel. A narrow reaction band was identified on the cladding side of the fuel-cladding interface. The band proved to have elevated concentration levels of $\mathrm{Zr}, \mathrm{Ce}, \mathrm{Pr}, \mathrm{Nd}, \mathrm{La}$, and $\mathrm{Sm}$, and was heavily depleted in $\mathrm{Ni}$ and partially depleted in iron from the levels noted in the original unreacted cladding. On the fuel side of the fuel-cladding interface, discrete, globular, lanthanide-rich phases were detected. Some of these phases had relatively high levels of palladium.

\subsubsection{T159}

EPMA of this fuel element (U-16Pu-23Zr fuel with D9 clad) showed that even at a low burn-up of 3 at\% redistribution of fuel and fission product constituents results in elevated levels of $\mathrm{U}, \mathrm{Pu}$, $\mathrm{Zr}$ and fission products at the fuel-cladding interface. Little evidence of actual fuel-cladding interaction was observed in this fuel element.

\subsubsection{A850}

Fuel element A850 consisted of U-16Pu-23Zr fuel and D9 cladding and was irradiated to 11.3 at\% burn-up. A total of seven samples were analyzed from this as-irradiated pin and in Table 6 the maximum cladding wastage observed for each specimen is correlated with the axial position ( $\mathrm{x} / \mathrm{L}$ ), the local burn-up, and the cladding ID temperature. Typically the largest interaction zones in this element were observed where a "wedge-shaped" crack had formed in the fuel adjacent to the inner surface of the cladding and a large fission product deposit (primarily $\mathrm{Nd}$, Ce, and La) had formed (Fig. 6).

Table 6. As-Irradiated Data For Samples From Fuel Element A850

\begin{tabular}{|c|c|c|c|c|}
\hline $\begin{array}{c}\text { Axial } \\
\text { Position } \\
(\mathrm{x} / \mathrm{L})\end{array}$ & $\begin{array}{c}\text { Local } \\
\text { Burn-up } \\
(\mathrm{at} \%)\end{array}$ & $\begin{array}{c}\text { Linear Power } \\
(\mathrm{kW} / \mathrm{ft})\end{array}$ & $\begin{array}{c}\text { Cladding } \\
\text { ID Temp. } \\
(\mathrm{C})\end{array}$ & $\begin{array}{c}\text { Maximum } \\
\text { Interaction } \\
\text { Zone } \\
\text { Thickness } \\
(\mu \mathrm{m})\end{array}$ \\
\hline \hline 0.5 & 11.4 & 15.1 & 518 & 47 \\
\hline 0.6 & 11.1 & 14.8 & 532 & 75 \\
\hline 0.7 & 10.6 & 14.2 & 543 & 126 \\
\hline 0.78 & 10.1 & 13.5 & 552 & 100 \\
\hline 0.9 & 9.1 & 12.1 & 562 & 90 \\
\hline 0.95 & 8.7 & 11.5 & 566 & 103 \\
\hline 1.0 & 8.2 & 10.9 & 570 & 75 \\
\hline
\end{tabular}




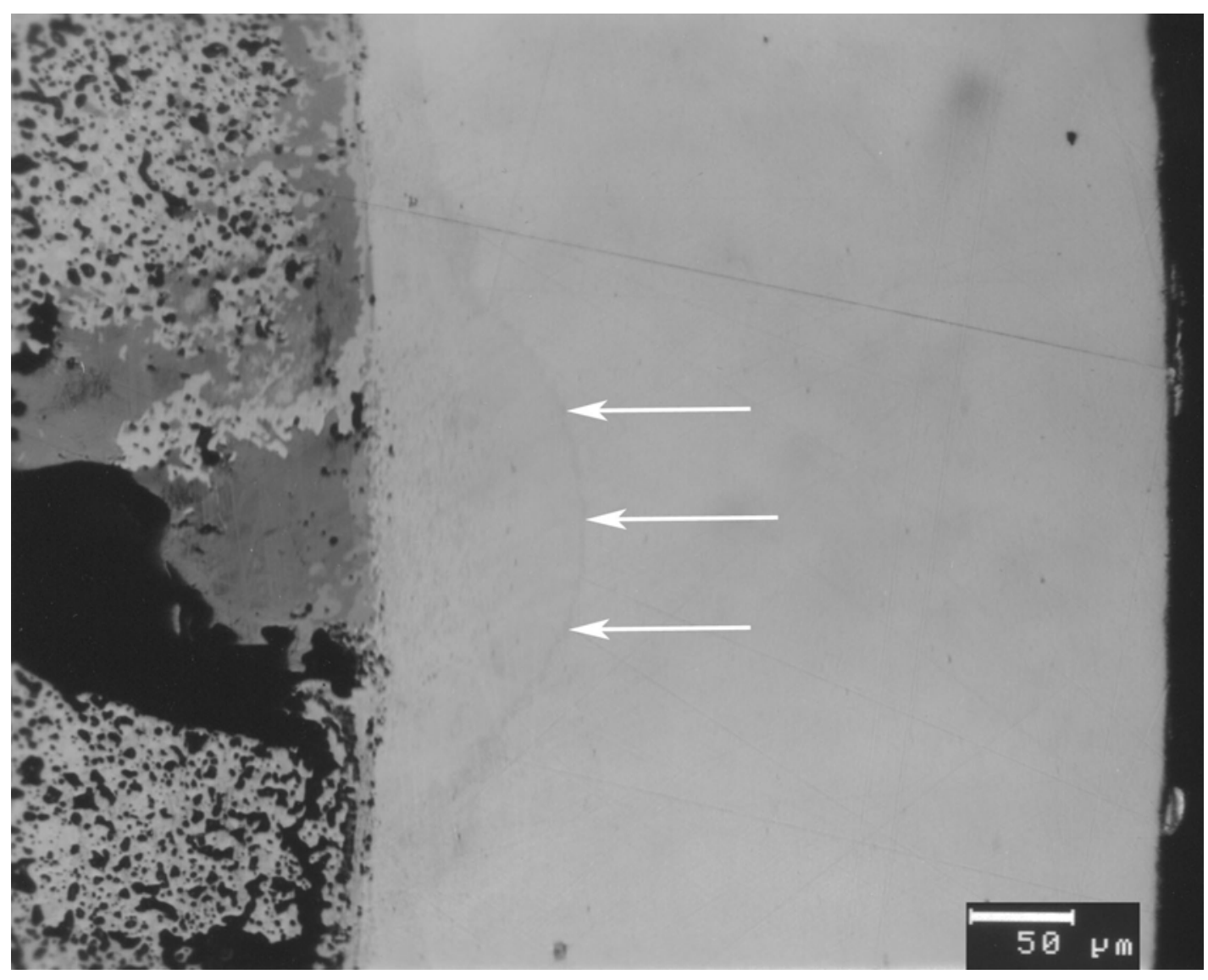

Fig. 16. Optical Micrograph Showing Fuel-Cladding Interaction (white arrows) Adjacent to a Large Deposit of Lanthanide Fission Products

For a sample taken at $\mathrm{x} / \mathrm{L}=0.78$, three different areas were analyzed at the fuel-cladding interface. The first area that was analyzed was near a "wedge-shaped" crack in the fuel that had been filled in with fuel. The second area contained a thin band (about $40 \mu \mathrm{m}$ thick) of lanthanides sandwiched between the fuel and the cladding. The last location was near a fuel crack, like that seen in Fig. 16. The bulk of the iron diffusion was observed in the first area analyzed. At the "wedge-shaped" crack location, iron penetrated into the fuel to a maximum depth of about $175 \mu \mathrm{m}$, and the concentration of iron in local spots in the fuel was as high as $25 \mathrm{wt} \%$. No iron penetration into the fuel was observed at the other two analyzed areas.

Nickel interdiffuson was observed in all three locations analyzed (about 180 to $200 \mu \mathrm{m}$ into the fuel) leaving a nickel depleted layer in the cladding; the nickel concentrations varied between 6 and $12 \mathrm{wt} \%$ in the fuel. Zirconium and nickel appeared to collocate in the fuel especially adjacent to the cladding. With regards to plutonium behavior, the high concentrations of nickel corresponded to local depletions of plutonium in the fuel, while in the cladding, elevated levels of plutonium were observed in the nickel depleted region. The highest amount of plutonium interdiffusion was observed in the first area analyzed. Here was noted the highest levels of iron depletion from the cladding and the most elevated concentration levels for $\mathrm{Pu}$ in the cladding. The lanthanide interdiffusion behavior appeared to mirror that of the plutonium, and they were 
found to interdiffuse to similar depths in the cladding. Cerium and neodymium were the most abundant lanthanides at all three locations, and lanthanum was the only other fission product observed in a measurable concentration. Uranium and zirconium did not penetrate into the cladding at any of the locations analyzed. The maximum lanthanide penetration was seen where lanthanide phases appeared to be in direct contact with the cladding.

As was the case for fuel element DP16 (an HT9 clad element), two differing contrast phases were observed in the vicinity of the fuel-cladding interface in element A850. These phases contained differing amounts of lanthanides; the lightest phase also contained palladium and ruthenium. For the sample sliced at an $\mathrm{x} / \mathrm{L}$ position of 0.6 , the boundary between the light and dark phases was seen around $200 \mu \mathrm{m}$ from the fuel-cladding interface. For $\mathrm{x} / \mathrm{L}$ positions of 0.7 and 0.95 , the boundary was observed 170 and $150 \mu \mathrm{m}$, respectively, from the interface. The 0.95 position was the highest temperature region of the pin, and this is where the light and dark phases seemed to be closest to the cladding. Therefore, the local temperature in a fuel element appears to control how close the light and dark phases will be observed in relation to the fuel-cladding interface.

\subsubsection{T042}

For the sample from element T042 (which was irradiated to 6 at\% burn-up), approximately $20 \mu \mathrm{m}$ of interaction was observed along with the presence of lanthanide fission products in the interaction zone. T042 was the only element analyzed that had a fuel alloy with a composition of U-7Pu-23Zr. Another fuel element that was analyzed after 6 at\% burn-up had U-16Pu-23Zr fuel (no identifying number for this element could be found); the maximum amount of interaction equaled $75 \mu \mathrm{m}$. Lanthanide fission products were observed in the interaction zone along with evidence of $\mathrm{Ni}$ and Fe depletion. The $\mathrm{Ni}$ was depleted to around $1 \mathrm{wt} \%$ from the original $16 \mathrm{wt} \%$ that existed in the original cladding, and the Fe was depleted from $67 \mathrm{wt} \%$ to $59 \mathrm{wt} \%$.

\subsubsection{D9-Clad Elements with Binary U-Zr Alloy Fuel}

\subsubsection{T141}

In fuel element T141 (U-23Zr fuel, D9 cladding, 11.9 at\% burn-up) the original Zr-rind from the injection casting of the fuel provided protection from fuel-cladding interaction. As shown in Fig. 17, interaction layers were only observed in the cladding in areas where the Zr-rind had failed. The maximum interaction layer thickness $(25 \mu \mathrm{m})$ was observed in the sample taken from the hottest region of the pin (an axial position of 14.25). This area of maximum interaction layer formation is presented in Fig. 18. Near the cladding, small amounts of fission product-containing phases were observed, may be due to the high amounts of fuel porosity that was observed near the cladding. As discussed earlier, T112, a fuel element with U-16Pu-23Zr fuel and D9 cladding, was also irradiated to 11.9 at\% burn-up (just like T141). Yet, T141 had a smaller interaction zone, which may be correlated to it having binary U-23Zr fuel. 

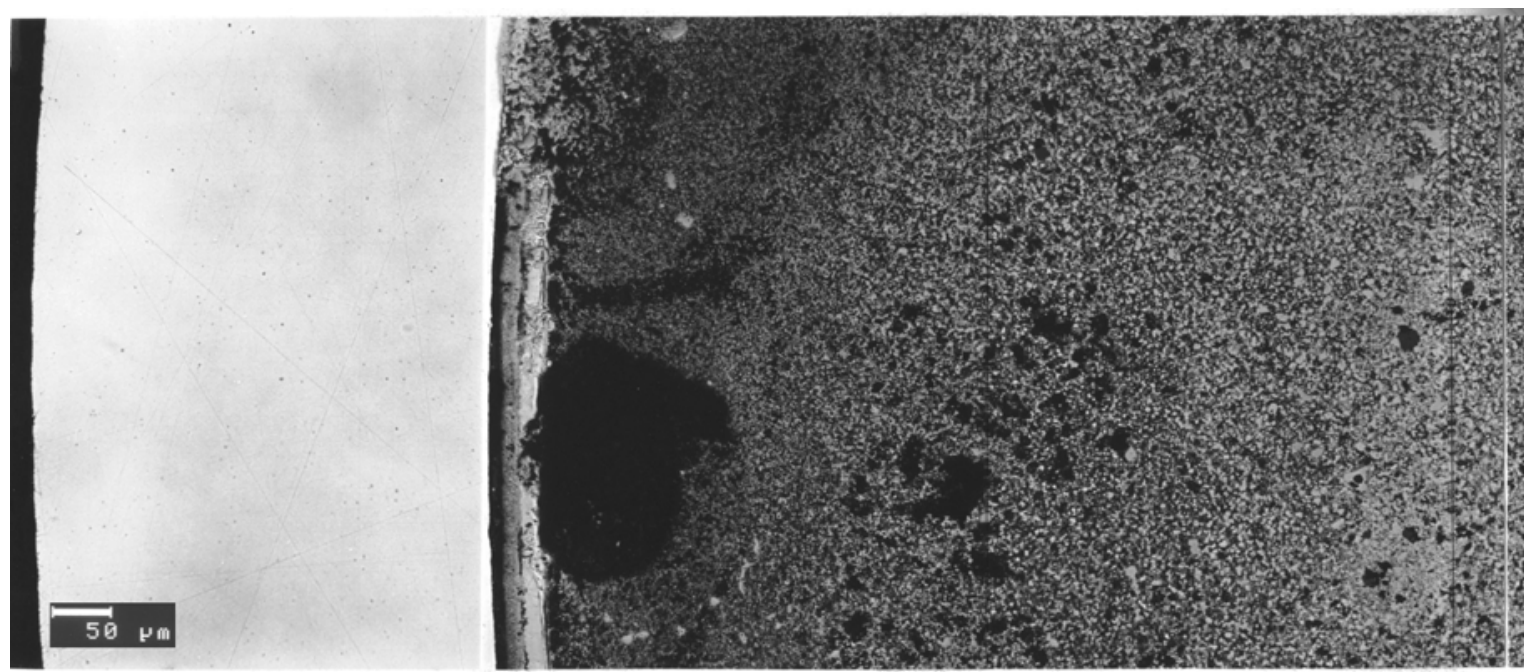

(a)

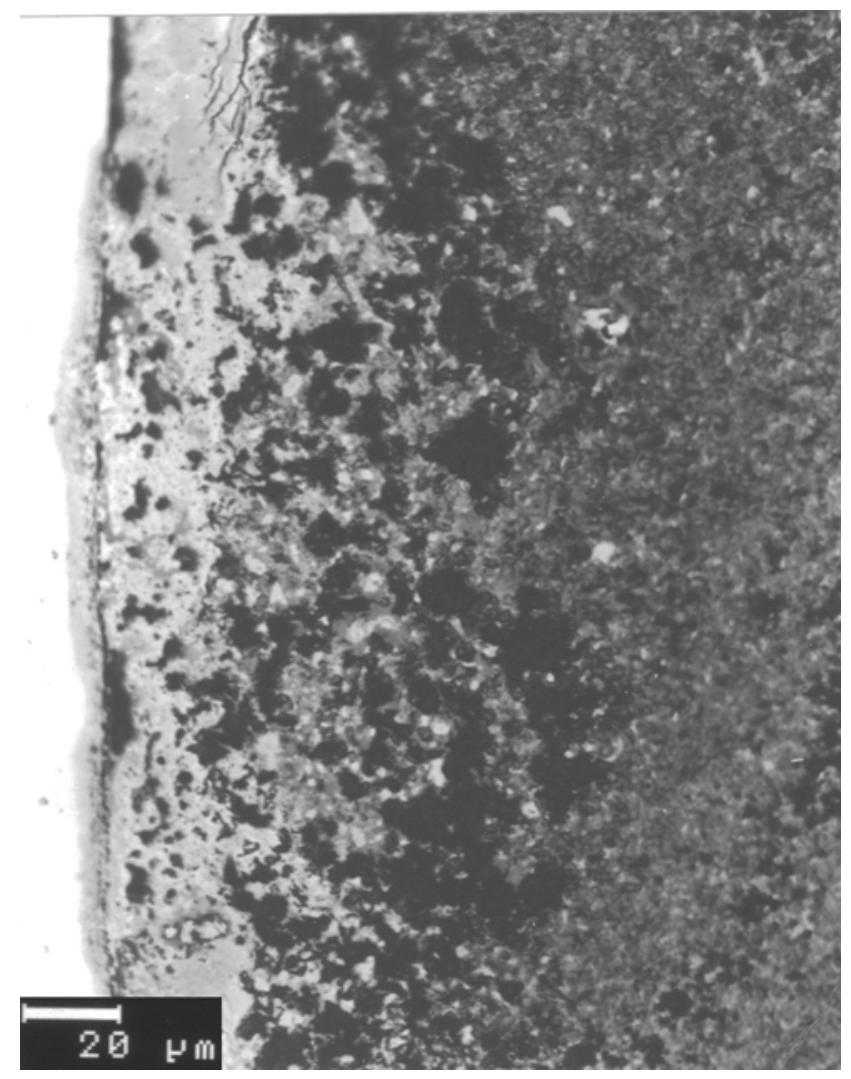

(b)

Fig. 17. Optical Micrographs Showing A Low Magnification Image (a) and High Magnification Image (b) of the Fuel-cladding Interface Where The Zr-rind Is Not Intact and Interaction Has Occurred Between the Fuel and Cladding 


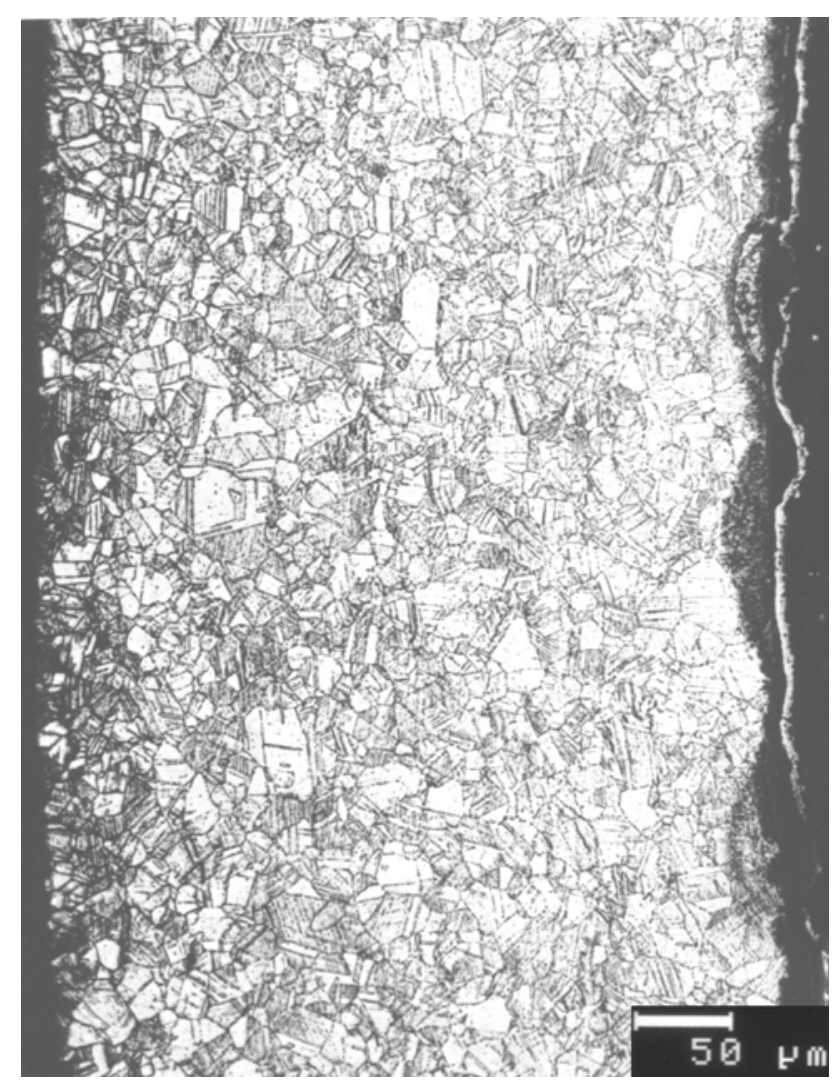

Fig. 18. Optical Micrograph Showing the Fuel-cladding Interaction That Has Occurred in an Area Where the Zr-rind Is Not Intact (the fuel side of the cladding is to the right)

\subsubsection{T225}

The observed interaction between fuel and cladding in fuel element T225 (U-23Zr fuel, D9 cladding, 10 at\% burn-up), as was the case for T141, is dependent on the integrity of the Zr-rind. Little interaction is observed in areas where the Zr-rind is intact, but in cases where the rind is degraded some interaction is observed (Fig. 19). A maximum interaction zone size of $25 \mu \mathrm{m}$ was observed in areas near the top of this fuel element. 


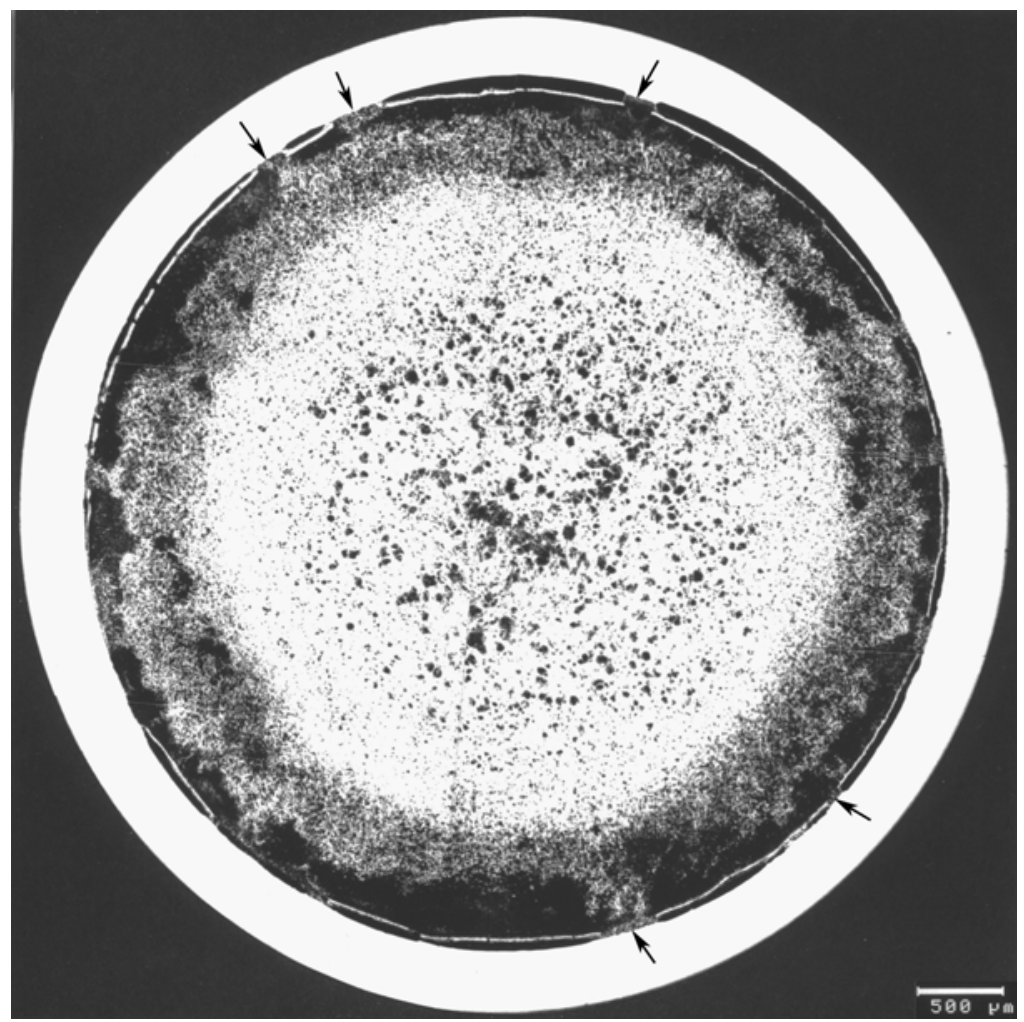

(a)

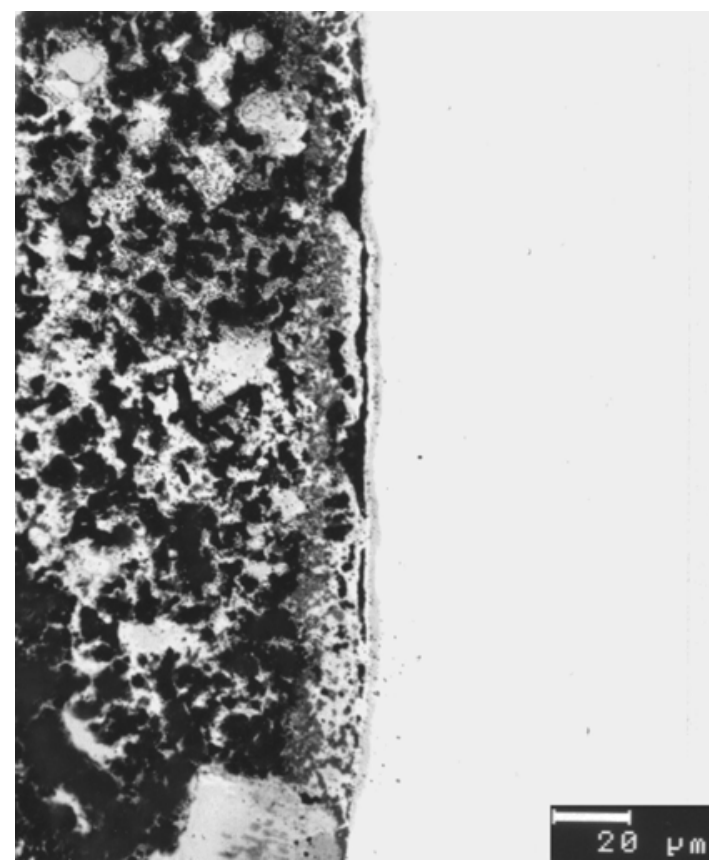

(b)

Fig. 19. Optical Micrographs of a Transverse Cross-section Taken From The Bottom of Element T-225 (figure (a) is a low magnification image where the black arrows identify some of the areas where the Zr-rind is not intact and fuel-cladding interaction has occurred, figure (b) is a higher magnification image of one of these areas) 


\subsubsection{C709}

In a transverse cross-section taken from element C709 (U-23Zr fuel, D9 cladding, 9.3 at\% burnup), two regions near the fuel-cladding interface were analyzed using EPMA. In both regions, complex multiphase diffusion structures were noted. By moving through the interaction zone starting with the un-reacted cladding and going towards the fuel, the first phase layer that was observed contained Fe, Cr, and some lanthanides (no Ni). The next layer consisted of Fe, Cr, lanthanides and some Ni. This layer was followed by two lanthanide layers with and without Pd and Sn (the layer without Pd and Sn was towards the cladding), and a layer containing $\mathrm{Zr}$, Ni, and $\mathrm{Fe}$ (and some $\mathrm{Si}$ ). Closest to the un-reacted fuel was a multiphase layer, where the matrix phase was enriched in U. A precipitate phase containing $\mathrm{Zr}$, Ni, and Fe was present on the clad-side of the layer, and a precipitate phase containing only Zr and Ni was present closer to the center of the fuel element. Lanthanides were not present in high amounts on the clad-side of this zone but were observed towards the fuel-side.

The second region of the sample that was analyzed had similar interdiffusion zones compared to the first. Again going from the un-reacted cladding towards the fuel center, the layers observed included: (1) a layer containing Fe and $\mathrm{Cr}$ (with negligible $\mathrm{Ni}$ ); (2) a layer with $\mathrm{Fe}, \mathrm{Nd}$, Ce, La, and minor amounts of Ni; (3) a Zr-rich layer with Ni and smaller amounts of Fe; (4) phase with Nd, Ce, La, and Pd; (5) a U layer with Fe + Zr precipitates (the layer was devoid in lanthanides); and (6) a layer with a U-matrix and lanthanide phases, $\mathrm{Zr}+\mathrm{Ni}$ phases, and Fe+Zr phases.

\section{Discussion}

\subsection{Phases Found at the Fuel-Cladding Interface in Irradiated U-Zr and U-Pu-Zr Fuel Elements Clad with D9, Type 316, or HT9 Stainless Steel}

Based on the results from analyses of fuel elements with U-Zr and U-Pu-Zr alloy fuels and D9, Type 316, and HT9 stainless steel cladding that were irradiated in EBR-II, a variety of phases have been observed to form locally where swelled fuel has contacted the cladding. At the interface between the fuel and the cladding, the observed phases on both sides of the interface combine the cladding elements $\mathrm{Fe}, \mathrm{Ni}$, and $\mathrm{Cr}$ with the fuel components $\mathrm{U}, \mathrm{Zr}$, and $\mathrm{Pu}$ and the lanthanide fission products. Some of these phases near the fuel-cladding interface contain Pd and $\mathrm{Ru}$.

Looking at the cladding-side of the original fuel-cladding interface, the developed phases are enriched in cladding components and they contain differing amounts of the primary fuel components (U, Pu, and $\mathrm{Zr}$ ) and fission product components. The lanthanide fission products are observed to penetrate furthest into the cladding (Ce and $\mathrm{Nd}$ appear to penetrate the furthest), in both HT9 and D9-clad fuel elements. This penetration results in the development of phases containing $\mathrm{Ce}, \mathrm{Nd}$, and La nearest the un-reacted cladding.

Fuel element DP16 (U-16Pu-23Zr fuel and HT9 cladding) was the fuel element analyzed in the greatest detail (using OM, SEM, and EPMA), and it provided the most information for trying to determine specific phases that may form on the cladding-side of the fuel-cladding interface. In particular, a lanthanide-Fe type of intermetallic phase, linked to the binary Ce-Fe phase diagram, may be the most likely phase to develop nearest the unreacted cladding. Tortorici and Dayananda 
[7] determined via a diffusion couple technique that when a diffusion couple between HT9 and Ce is assembled and annealed at $425^{\circ} \mathrm{C}$ for seven days two single-phase layers form. Of the two layers, the phase layer adjacent to the un-reacted cladding is similar in composition and morphology to the one observed for fuel element DP16 (layer 4 in Table 1). By ratioing the Ce concentration (13 at\%) with the sum of the concentrations for the cladding components [Fe $(71$ at\% $)+\operatorname{Cr}(16$ at\% $)+\mathrm{Ni}(<1$ at\%)], Tortorici and Dayananda determined this phase layer to be a $\mathrm{Ce}_{2}(\mathrm{Fe}+\mathrm{Cr}+\mathrm{Ni})_{17}$ phase. (A (lanthanide) ${ }_{2} \mathrm{Fe}_{17}$ is the only possible intermetallic phase that can form at lower lanthanide concentrations based on binary phase diagrams between Fe and the lanthanides Ce, $\mathrm{Nd}$, Sm, and Pr. La when combined with Fe does not form a $\mathrm{La}_{2} \mathrm{Fe}_{17}$ phase, and lanthanum is not observed in noticeable levels in what has been labeled the (lanthanide $)_{2}(\mathrm{Fe}+\mathrm{Cr}+\mathrm{Ni})_{17}$ phase in $\mathrm{DP} 16$. Based on the same phase diagrams, the likely intermetallic to form at higher lanthanide concentrations is a (lanthanide) $\mathrm{Fe}_{2}$ phase.) This phase is similar to the $\mathrm{Ce}_{2} \mathrm{Fe}_{17}$ described in the Ce-Fe binary phase diagram [8]. Using the same approach for labeling the phase layer that forms adjacent to the un-reacted cladding in the DP16 fuel element, layer 4 in Fig. 6 and Fig. 7 appears to also consist of a $(\mathrm{Ce}+\mathrm{Nd})_{2}(\mathrm{Fe}+\mathrm{Cr}+\mathrm{Ni})_{17}$ phase.

Besides the $(\mathrm{Ce}+\mathrm{Nd})_{2}(\mathrm{Fe}+\mathrm{Cr}+\mathrm{Ni})_{17}$ phase, other types of phases appear on the cladding-side of the fuel-cladding interaction zone in DP16 that have different ratios of cladding components to lanthanides. These phases also contain $\mathrm{Pu}$ and $\mathrm{Pd}$, and minor amounts of other components. In DP16 and the other analyzed fuel elements, deep penetration of Pu into the cladding is observed, along with penetration of U. Zr does not penetrate far, but instead stays near the original fuelcladding interface and combines with primarily cladding components to form Zr-rich phases.

On the fuel-side of the fuel-cladding interaction zone, some phases are observed that are enriched in the fuel constituents $\mathrm{U}, \mathrm{Pu}$, or $\mathrm{Zr}$ and contain $\mathrm{Fe}$ or $\mathrm{Ni}$ as the major non-fuel or components (with some lanthanides). Other phases are observed that contain primarily lanthanides. When the low-nickel stainless steel HT9 is employed as cladding in a fuel element, Fe is observed to penetrate the deepest into the fuel of any cladding constituent. As a result, the phases found on the fuel-side of the interface in these fuel elements contain more Fe than any other cladding component. The fuel component that appears to combine with the Fe is Zr. For fuel elements clad with the austenitic stainless steel D9, Ni diffuses much further into the fuel, and it is found to combine with Zr. Fe also diffuses into the fuel and forms phases. An Fe and Ni depletion zone is observed in all the fuel elements, with the depletion of the Ni extending further into the cladding than the depletion of the Fe.

Pd is the non-lanthanide fission product that is found to interdiffuse farthest into the cladding. Looking at the results from DP16, the phase layer with the most Pd also had levels of Ce, Nd, and $\mathrm{Pu}$ that were also reasonably high. In a case where Pd did not penetrate far into the cladding, the $\mathrm{Pd}$ was found in a phase layer where the $\mathrm{Ce}$ and $\mathrm{Nd}$ levels were still high but the $\mathrm{Pu}$ concentration had dropped off and the Zr concentration was high. From binary phase diagrams that combine the lanthanides Ce or $\mathrm{Nd}$ with Pd, it is observed that many intermetallic phases can form between any lanthanide and Pd. In layers 1 and 3 of the DP16 SEM sample shown in Fig. 6, notable amounts of $\mathrm{Ce}, \mathrm{Nd}$, and Pd are detected. These concentration levels could be indicating 
the formation of one or more $(\mathrm{Ce}+\mathrm{Nd})-\mathrm{Pd}$ phases that have some solid solubility for other fuel and cladding constituents.

\subsection{Factors Affecting Interaction Zone Thickness in Irradiated Fuel Elements}

In general, interaction zone formation is localized. In many of the analyzed fuel elements, fuelcladding interaction can be linked to the integrity of the Zr-rind. In cases, where the Zr-rind is failed, some of the thickest interaction zones can be observed. The Zr-rind is most likely to remain intact in fuel elements exposed to lower temperatures and lower power.

Both temperature and power variations along the length of a fuel element appear to impact the amount of fuel-cladding interaction that will occur. The temperature increases along the length of a fuel element and reaches a maximum at the top. The power variation is a dropped cosine. The fuel element region exposed to the maximum power and temperature combination is located near an $\mathrm{x} / \mathrm{L}$ position of 0.80 . The maximum fuel-cladding interaction is observed in this combined high temperature and high power region of a fuel element. In this region of a fuel element, the interdiffusion kinetics are increased and the supply of fission products at the fuel-cladding interface is large. The result can be some of the largest observed interaction zones.

The burn-up of a fuel pin is another parameter that impacts the size of the fuel-cladding interaction zone. Larger interaction zones are observed for higher-burn-up fuel elements. One reason for the larger zone size is the larger inventories of fission products that are available at the fuel-cladding interface in high-burn-up fuel elements. More lanthanides diffuse down the temperature gradient that exists from the center towards the outer edge of a fuel element thereby increasing the inventory of fission products at the interface. Also, a high-burn-up fuel element has been at relatively high temperatures for long periods of time, resulting in more available time for interdiffusion between fuel and cladding components to occur. Another fuel element attribute that impacts fuel-cladding interaction is the position of a fuel element in the core of the reactor, since this helps determine the burn-up of the fuel element. In addition, the peak inner cladding temperature will vary based on core position, and this will impact the interdiffusion kinetics. Fuel elements at the hotter core positions can exhibit increased interdiffusion at the fuel-cladding interface over those at colder positions.

\subsection{Potential Components to be Carried Over into a Metal Waste Form}

As mentioned earlier, when fuel elements are chopped into small segments and placed into an electrorefiner to dissolve away the U-Zr or U-Pu-Zr alloy fuel, conditions will be controlled so that the cladding hulls, $\mathrm{Zr}$, and noble metal fission products will be purposefully left behind in the anode dissolution baskets. The leftover material will then be cast into a metal waste form. Based on the investigation described above, a potential exists for an additional carryover, with the cladding hulls, of some non-noble-metal fission products and non-Zr fuel components. The non-noble-metal fission products include the lanthanide elements and the non-Zr fuel constituents include $\mathrm{U}$ and $\mathrm{Pu}$.

The potential for carryover would be most likely for the fuel elements with the largest fuelcladding interaction zones, i.e. the high-burn-up fuel elements. In the high-burn-up fuel elements, the largest fuel-cladding interaction zones should exist in the highest temperature 
regions of the fuel element. Even in these high-burn-up fuel elements, any carryover of lanthanides, U, or Pu would only be in very minor amounts, based on the size of the interaction layers that have been observed to form in analyzed fuel elements. On the other hand, if electrorefiner conditions are favorable, the interaction layers that can exist on the inner surfaces of cladding hulls will dissolve, and the lanthanides, $\mathrm{U}$, and $\mathrm{Pu}$ will not be present with the cladding hulls, and will not be incorporated into the metal waste form.

\section{Conclusions}

Results from the destructive analyses of nineteen irradiated fuel elements from EBR-II have been assessed in the context of fuel-cladding interaction. Based on these results, the following conclusions can be made:

1. Of the fuel and fission product constituents, the lanthanide fission products penetrate the deepest into HT9 and D9 cladding; these components form phases with $\mathrm{Fe}, \mathrm{Ni}$, and $\mathrm{Cr}$.

2. For fuel elements with U-Pu-Zr alloy fuel, Pu is the primary fuel constituent that penetrates furthest into the cladding; for $\mathrm{U}-\mathrm{Zr}$ alloy fuel, $\mathrm{U}$ penetrates the deepest into the cladding.

3. Of the cladding constituents, Fe and $\mathrm{Ni}$ are observed to diffuse into the fuel to form phases with $\mathrm{U}, \mathrm{Pu}$, and $\mathrm{Zr}$. A significant Ni-depletion band is observed to form in the austenitic cladding, D9. Cr becomes enriched at the fuel-cladding interface and does not penetrate far into the fuel.

4. Near the fuel-cladding interface, light and dark contrast phases can be observed on the fuel-side of the interface that contain lanthanide fission products and Pd. Blocky particles containing $\mathrm{Zr}$, Mo, Tc, $\mathrm{Ru}, \mathrm{Rh}$, and $\mathrm{Pd}$ are observed in the fuel near the cladding.

5. The Zr-rind in the fuel is a barrier to fuel-cladding interaction, and it is most likely to remain intact in fuel elements exposed to relatively lower temperatures and lower power.

6. Maximum fuel-cladding interaction occurs at the combined high power and high temperature region of a fuel element. The largest penetrations into the cladding are observed for fuel elements with ternary U-Pu-Zr fuel and D9 cladding.

7. If interaction layers that reside on the inner surface of cladding hulls do not dissolve in the electrorefiner, then minor amounts of lanthanide fission products, $\mathrm{U}$, and $\mathrm{Pu}$ will be found in the metal waste form. 


\section{Acknowledgments}

The support of the U. S. Department of Energy under contract W-31-109-ENG-38 is gratefully acknowledged. Adam Cohen is acknowledged for his assistance in collecting information to include in this report. 


\section{REFERENCES}

1. J. E. Battles, J. J. Laidler, C. C. McPheeters, and W. E. Miller, "Pyrometallurgical Process for Recovery of Actinide Elements,” Actinide Processing: Methods and Materials, 135-151, The Minerals, Metals, \& Materials Society, Warrendale, PA (1994).

2. C. Pereira, M. A. Lewis and J. P. Ackerman, “Overview of Mineral Waste Form Development for the Electrometallurgical Treatment of Spent Nuclear Fuel," Proc. of the Embedded Topical on DOE Spent Nuclear Fuel and Fissile Material Management, Reno, NV, 129, (June 16-20, 1996).

3. S. M. McDeavitt, D. P. Abraham, and D. D. Keiser, Jr., “Alloy Waste Forms for Metal Fission Products and Actinides Isolated by Spent Nuclear Fuel Treatment," Proceedings of the Second International Symposium on Extraction and Processing for the Treatment and Minimization of Wastes, Scottsdale, AZ, 177, (Oct. 27-30, 1996).

4. G. L. Hofman and L. C. Walters "Metallic Fast Reactor Fuels" Materials Science and Technology: A Comprehensive Treatment, 10:1-43, VCH Publishers Inc. (1994).

5. R. G. Pahl, D. L. Porter, C. E. Lahm, and G. L. Hofman, "Experimental Studies of U-Pu-Zr Fast Reactor Fuel Pins in the Experimental Breeder Reactor-II,” Met. Trans. 21A-1863 (1990).

6. R. G. Pahl, C. E. Lahm, and S. L. Hayes, "Performance of HT9 Clad Metallic Fuel at High Temperatures,” J. Nucl. Mater. 204:141 (1993).

7. P. C. Tortorici and M. A. Dayananda, "Interdiffusion of Cerium in Iron-Nickel-Chromium Alloys,” Thesis, Purdue University, (May 1993).

8. T. B. Massalski, Binary Alloy Phase Diagrams, Second Edition, American Society of Metals, Materials Park, OH,1058 (1990). 